\title{
A comparison between statistical analysis and grey model analysis on assessed parameters of petroleum potential from organic materials
}

\author{
Hsien-Tsung Lee \\ Department of Electrical and Information Technology, NanKaiUniversity of Technology, Nan Tou County, Taiwan
}

Email address:

t114@nkut.edu.tw

To cite this article:

Hsien-Tsung Lee. A Comparison between Statistical Analysis and Grey Model Analysis on Assessed Parameters of Petroleum Potential from Organic Materials. Journal of Energy and Natural Resources. Vol. 4, No. 1, 2015, pp. 5-26. doi: 10.11648/j.jenr.20150401.12

\begin{abstract}
This study aims to investigate the impact of changes in the Tmax and Ro\% on the assessed parameters (S1, S2, S1+S2, HI, QI, BI, PI, TOC) of petroleum potential of organic materials. The samples studied include coals and coaly shales of Mushan Formation, Shihti Formation and Nanchuang Formation in NW Taiwan, coals and an oil shale from Mainland China, the well-drilled chip samples from NW Australia, in addition to the data of samples were included from literatures. This work will get on the detecting data of 10 parameters (S1, S2, S1+S2, TOC, HI, QI, BI, PI, Ro\%, Tmax) and progressing statistical analysis, and focus the study on comparison between grey forecast of grey relational grade and regression model forecast. The results from statistical analysis (include temperature-treated samples were individually subjected to Rock-Eval analysis) of the all parameters data for all samples in this research project, not only be executed a linear regression, curve regression between any two parameters, and multivariate regression, but also be carried on the forecast of grey correlation grade of grey theory (include grey relational generating (Nominal-the-better-:Ro\%; Larger-the-better-: Tmax, HI, QI, BI, S2, S1+ S2, S1; smaller-the-better-: TOC, PI) and globalization grey relational grade). So far, obtain roughly the consistency of results from two type predictive analysis. The constructed HI, QI and BI bands were broad at low maturities and gradually narrowed with increasing thermal maturity. The petroleum generation potential is completely exhausted at a vitrinite reflectance of $2.0-2.2 \%$ or a $\mathrm{T}_{\max }$ of $510-520^{\circ} \mathrm{C}$. An increase in HI and QI suggests extra petroleum potential related to changes in the structure of the organic material. A decline in BI signifies the start of the oil expulsion window and occurs within the vitrinite reflectance range $0.75-1.05 \%$ or a $\mathrm{T}_{\max }$ of $440-455{ }^{\circ} \mathrm{C}$. Furthermore, petroleum potential can be divided into four different parts based on the cross-plot of HI vs. $\%$ Ro. The area with the highest petroleum potential is located in section II with $\%$ Ro $=0.6-1.0 \%$, and HI $>100$. Oil generation potential is rapidly exhausted at section III with $\%$ Ro $>1.0 \%$. This result is in accordance with the regression curve of $\mathrm{HI}$ and QI with \%Ro based on 97 samples with $\% \mathrm{Ro}=1.0 \sim 5.6 \%$.
\end{abstract}

Keywords: Vitrinite Reflectance (Ro \%), Grey Relational Analysis, Grey Model, Rock-Eval Pyrolysis, Petroleum Potential, Statistical Analysis

\section{Introduction}

Petroleum potential of source rocks is described in terms of quantity, quality and level of thermal maturity of organic material (Bordenave et al., 1993; Lee, 2011). Rock-Eval pyrolysis (Espitalie' et al., 1977, 1985; Lee, 2011; Lee and Sun, 2013) is an effective method for the assessment of petroleum potential in source rocks as well as for the geochemical characterization of organic material.Rock-Eval pyrolysis is rapid, inexpensive, requires only small amounts of material, and can generate reliable data. Teichmüller (1973) and Vassoevich et al. (1974) proposed a vitrinite reflectance range from $0.5-0.55 \%$ Ro to $1.3 \%$ Ro for the oil window, although it is expanded from $0.5-0.6 \%$ Ro to $1.3-1.35 \%$ Ro by authors such as Hunt (1996), Petersen (2002), Peters and Cassa (1994), Taylor et al. (1998), and Tissot et al.(1987).Furthermore, Vassoevich et al. (1974) determined that oil generation occurs at a vitrinite reflectance of $0.5 \%$ Ro, whereas oil cracking starts to occur at a vitrinite reflectance of approximately $1.3 \%$ Ro. The temperature at the peak of S2 is referred to as Tmax. The total genetic potential of the sample is defined as $\mathrm{S} 1+\mathrm{S} 2$. The total genetic potential of organic matter in the synthetic assessment of the petroleum potential is described using the hydrogen index (HI, S2/TOC), 
the bitumen index (BI, S1/TOC) (Killops et al., 1998) and the quality index (QI, [S1+S2]/TOC) (Pepper and Corvi, 1995). The commencement of the effective oil window corresponds to the maturity at which BI begins to decrease during maturation, leading to efficient oil expulsion.

The maturity of organic matter is one of the most important parametersin the evaluation of oil-gas (Tissot and Welte, 1984; Lee, 2011). In assessing maturity of organic matter, vitrinite reflectance $(\%$ Ro) is the most commonly examined parameter. Three major characters need to be studied in order to determine the petroleum potential of source rock: properties of organic material, process of thermal maturation, and abundance of hydrocarbon. However, high pressures during hydrocarbon formation increase the activation energies of organic matter in chemical reactions, which may lead to the suppression of vitrinite reflectance. In addition, vitrinite reflectance is strongly influenced by oxidation, so care must be taken to avoid over or under estimating the maturity. Therefore, the maturity parameters of hydrocarbon must be explored in order to construct effective indices for the assessment of petroleum potential. Vitrinite reflectance is a widely used parameter as a geothermometer for the estimation of the thermal maturity. But problems such as human mistakes in measurement, technical problems, and problems associated with the structural and compositional heterogeneity of organic matter. In most cases, the first two types of uncertainties can be handled by standardization (ASTM, ISO). The third problem needs to be solved by statistical analysis.

The anomalously high HI values of coal samples can lead to an overestimation of the hydrocarbon potential. Peters(1986) suggested that the hydrocarbon potential of coal is best determined by using elemental and petrographic analysis. Several succeeding studies evaluated HI and S2 as predictors of the hydrocarbon potential by correlating them with the atomic $\mathrm{H} / \mathrm{C}$. However, the results were not satisfactory. Powell et al (1991) found a relationship between $\mathrm{HI}$ and atomic $\mathrm{H} / \mathrm{C}$ for Australian coals with atomic $\mathrm{H} / \mathrm{C}$ in the range of 0.8-1.0. Petersen and Rosenberg (2000) studied the relationship between HI and \%Ro but only found a weak and negative correlation. Other researches exhibited that the HI value displays a strong correlations to volatile matter, which can also be considered as a substitute for petroleum generation potential (Suggate and Boudou, 1993; Newman et al., 1999; Lee, 2011; Lee and Sun, 2013).

After performing the vitrinite reflectance measurement and pyrolysis analysis of organic material, ten parameters \%Ro, Tmax, HI(S2/TOC), QI([S1+ S2]/TOC), BI(S1/TOC), $\mathrm{PI}(\mathrm{S} 1 /[\mathrm{S} 1+\mathrm{S} 2]), \mathrm{S} 2, \mathrm{~S} 1+\mathrm{S} 2$, TOC, and $\mathrm{S} 1$ can be obtained. They will show the characteristics of the organic material in evaluating their petroleum potential. In avoiding overestimate or underestimate of the generation potential of organic material, we will investigate the correlation among above respective parameter with the datasets of 608 and 506 samples in this research. On the other hand, maturity and types of organic material are related to \%Ro and all parameters, so we can estimate petroleum potential of organic material by the statistical analysis to evaluate correlativity among all aforementioned parameters. For the majority of organic material, present a more complex correlation between Rock-Eval parameters and maturity (rank). So we can also assess the evolution and petroleum potential of organic material by using cross-plots of maturity (\%Ro) and Rock-Eval parameters.

Meanwhile, the purpose of this study is to establish reliable indices for the synthetic assessment of organic matter in the evaluation of petroleum potential. The scope of this study will be focused on Rock-Eval pyrolysis, vitrinite reflectance measurement, TOC measurement, maceral composition analysis, regression model forecast, gray relational grade, multivariate statistical analysis and cross-plots of \%Ro and Tmax vs. above parameters according to data obtained from vitrinite reflectance measurements, TOC, and Rock-Eval pyrolysis. This study presents new guidelines for improved assessment of generative potential and thermal maturity.

\section{Methods of Experiment and Analysis}

Maceral analysis and vitrinite reflectance measurements were performed on polished pellets under a Leitz MPV Compact Microscope (light source 12V, 100W; wavelength $546 \mathrm{~nm}$; refractive index of soak oil, $\mathrm{Ne}=1.5180$ ). Opticalmicroscope was used to identify three main maceral groups (exinite, vitrinite and inertinite), as well as inorganic minerals (pyrite and clay minerals) through point counting. At least 100 measurements were made for each sample. Elemental Analysis and Rock-Eval Pyrolysis were performed in the Precise Instrument Center of National Science Council and EDRI of Chinese Petroleum Corp. respectively. All analytical works were carried out according to ISO or ASTM standards procedures. This study was performed by using the following procedures. The dataset of study starts from the collection of sample data including from literature and our own historical archives. The total number of samples is 1140 (1020 from literature and 120were analyzed for this study; database cf. Table1). Out of the1140 samples, only 608(Table1) have all 10 parameters (\%Ro, Tmax, HI, QI, BI, PI, S2, S1+ S2, TOC, and S1). The 120 samples include TW1-48 (from NW Taiwan), ML1-59 (from China), and AU1-13(from Australia).

The scope of this study will be focused on Rock-Eval pyrolysis, vitrinite reflectance measurement, TOC measurement, maceral composition analysis, elements analysis, regression model forecast, gray relational grade, and relative mathematical model. In addition, process new guidelines for improved assessment of the kerogen type, generative potential and thermal maturity using Rock-Eval parameters. Grey relational Analysis include grey generating, grey relational generating operation (Deng, 1988; Wen, 2004).

(1) Grey Generating $x_{i}^{*}(K)=\frac{x_{i}^{(0)}(K)}{\alpha}$
(2) GM $(1,1)$ Model $\frac{d x^{(1)}}{d t}+a x^{(1)}=b$ 
(3) Verhulst Model $\frac{d x^{(1)}}{d t}+a x^{(1)}=b\left(x^{(1)}\right)^{2}$

Vitrinite reflectance measurement and pyrolysis analysis were performed to evaluate the relationship between the petroleum potential and the maturity for the aforementioned 120 samples. And then go on statistical analysis and drawing cross-plot of the parameters (\%Ro, Tmax, HI, QI, BI, PI, S2, $\mathrm{S} 1+\mathrm{S} 2, \mathrm{TOC}$, and S1) in the datasets of 1140,608 , and 506 samples. In order to get the correlation between the aforementioned parameters and to evaluate synthetically the petroleum potential of organic material, can perform statistical analysis methods. Furthermore, the statistical analysis are performed with descriptive, correlation, independent samples T-test, linear and curve regression, factor, principal component, nonparametric tests by Excel and SPSS 16.0 (Keller, 2001; Zhang et al., 2007). All of the analyses were carried out on 10 parameters for the datasets of 608and 506 samples, and 3 parameters (\%Ro, Tmax, HI) for the dataset of 1140 samples. The total genetic potential of organic matter in the synthetic assessment of petroleum potential is evaluated by hydrogen index (HI, S2/TOC), bitumen index (BI, S1/TOC), and quality index (QI, $(\mathrm{S} 1+\mathrm{S} 2) / \mathrm{TOC})$.

Statistical methods used on this study include: descriptive, multiple discriminant analyses, Pearson's correlation, $\mathrm{K}$-Independence and 2-independent samples T-tests, linear and curve regression, $\mathrm{Q}$ and $\mathrm{R}$ mode hierarchical cluster analysis, and principal component analysis (PCA). The first step in the multivariate analyses was the construction of a Pearson correlation coefficient matrix using all of the geochemical parameters contained in the datasets. The most statistically significant variables in the datasets were thus identified.

Table 1. List of sample database (the dataset of 1140 samples).

\begin{tabular}{llll}
\hline Period & Region collected & Number & Notes \\
\hline Cenozoic & Poland, Australia, Indonesia, USA, New Zealand, Taiwan, China & 251 & $\mathrm{~b}, \mathrm{c}, \mathrm{d}, \mathrm{f}, \mathrm{h}, \mathrm{j}, \mathrm{o}, \mathrm{p}, \mathrm{q}, \mathrm{r}, \mathrm{t}, \mathrm{u}, \mathrm{s}$ \\
Cretaceous & Poland, Australia, Nigeria, China & 99 & $\mathrm{~b}, \mathrm{c}, \mathrm{h}, \mathrm{i}, \mathrm{m}, \mathrm{p}, \mathrm{t}, \mathrm{u}$ \\
Jurassic & China, Poland, Australia, NW China, New Zealand & 106 & $\mathrm{a}, \mathrm{b}, \mathrm{c}, \mathrm{e}, \mathrm{h}, \mathrm{l}, \mathrm{m}, \mathrm{p}, \mathrm{t}, \mathrm{u}$ \\
Triassic & China, NW China & 97 & $\mathrm{a}, \mathrm{c}, \mathrm{e}, \mathrm{n}$ \\
Permian & China, Poland, Australia, New Zealand, USA, Indonesia & 90 & $\mathrm{a}, \mathrm{b}, \mathrm{c}, \mathrm{h}, \mathrm{l}, \mathrm{m}, \mathrm{p}, \mathrm{q}, \mathrm{t}, \mathrm{u}$ \\
Carboniferous & China, Ukraine, NW China, Netherland & 497 & $\mathrm{a}, \mathrm{e}, \mathrm{g}, \mathrm{k}, \mathrm{t}$ \\
\hline
\end{tabular}

\begin{tabular}{|c|c|c|c|c|}
\hline \multirow{2}{*}{$\begin{array}{l}\text { Notes } \\
\text { a }\end{array}$} & \multicolumn{2}{|c|}{ Sample numbers } & \multirow{2}{*}{$\begin{array}{l}\text { Parameters detected } \\
\% \operatorname{Ro}, \operatorname{Tmax}\left({ }^{\circ} \mathrm{C}\right), \mathrm{HI}, \mathrm{QI}, \mathrm{BI}, \mathrm{PI}, \mathrm{S} 2, \mathrm{TOC}, \mathrm{S} 1+\mathrm{S} 2, \mathrm{~S} 1\end{array}$} & \multirow{2}{*}{$\begin{array}{l}\text { References } \\
\text { Chen, et al., } 2003\end{array}$} \\
\hline & CJ & $1 \sim 38$ & & \\
\hline $\mathrm{b}$ & $\mathrm{KM}$ & $1 \sim 17$ & $\begin{array}{l}\text { \%Ro, } \operatorname{Tmax}\left({ }^{\circ} \mathrm{C}\right), \mathrm{HI}, \mathrm{QI}, \mathrm{BI}, \mathrm{PI}, \mathrm{S} 2, \mathrm{TOC}, \mathrm{S} 1+\mathrm{S} 2, \mathrm{~S} 1 \\
2004\end{array}$ & Kotarba and Lewan, \\
\hline $\mathrm{c}$ & PT & $1 \sim 82$ & $\%$ Ro, $\operatorname{Tmax}\left({ }^{\circ} \mathrm{C}\right), \mathrm{HI}, \mathrm{TOC}, \mathrm{QI}, \mathrm{BI}, \mathrm{S} 1+\mathrm{S} 2, \mathrm{~S} 1, \mathrm{~S} 2$, QI & Powell et al., 1991 \\
\hline $\mathrm{d}$ & $\mathrm{AH}$ & $1 \sim 19$ & $\begin{array}{l}\% \operatorname{Ro}, \operatorname{Tmax}\left({ }^{\circ} \mathrm{C}\right), \mathrm{HI}, \mathrm{QI}, \mathrm{BI}, \mathrm{PI}, \mathrm{S} 2, \mathrm{TOC}, \mathrm{S} 1+\mathrm{S} 2, \mathrm{~S} 1 \\
2006\end{array}$ & Amijaya and Littke, \\
\hline e & $\mathrm{XM}$ & $1 \sim 48$ & $\%$ Ro, Tmax $\left({ }^{\circ} \mathrm{C}\right), \mathrm{HI}, \mathrm{QI}, \mathrm{BI}, \mathrm{PI}, \mathrm{S} 2, \mathrm{TOC}, \mathrm{S} 1+\mathrm{S} 2, \mathrm{~S} 1$ & Xiao et al., 2005 \\
\hline$f$ & $\mathrm{CU}$ & $1 \sim 47$ & $\begin{array}{l}\% \operatorname{Ro}, \operatorname{Tmax}\left({ }^{\circ} \mathrm{C}\right), \mathrm{HI}, \mathrm{QI}, \mathrm{BI}, \mathrm{PI}, \mathrm{S} 2, \mathrm{TOC}, \mathrm{S} 1+\mathrm{S} 2, \mathrm{~S} 1 \\
2004\end{array}$ & Canonico et al., \\
\hline $\mathrm{g}$ & PA & $1 \sim 71$ & $\begin{array}{l}\% \operatorname{Ro}, \operatorname{Tmax}\left({ }^{\circ} \mathrm{C}\right), \mathrm{HI}, \mathrm{QI}, \mathrm{BI}, \mathrm{PI}, \mathrm{S} 2, \mathrm{TOC}, \mathrm{S} 1+\mathrm{S} 2, \mathrm{~S} 1 \\
2003\end{array}$ & Sachsenhofer et al., \\
\hline h & KJ & $1 \sim 80$ & $\%$ Ro, $\operatorname{Tmax}\left({ }^{\circ} \mathrm{C}\right), \mathrm{HI}, \mathrm{QI}, \mathrm{BI}, \mathrm{PI}, \mathrm{S} 2, \mathrm{TOC}, \mathrm{S} 1+\mathrm{S} 2, \mathrm{~S} 1$ & Kotarba et al., 2002 \\
\hline i & AS & $1 \sim 35$ & $\%$ Ro, Tmax $\left({ }^{\circ} \mathrm{C}\right), \mathrm{HI}, \mathrm{QI}, \mathrm{BI}, \mathrm{PI}, \mathrm{S} 2, \mathrm{TOC}, \mathrm{S} 1+\mathrm{S} 2, \mathrm{~S} 1$ & Akande et al., 1998 \\
\hline j & $\mathrm{NC}$ & $1 \sim 22$ & $\%$ Ro, $\operatorname{Tmax}\left({ }^{\circ} \mathrm{C}\right), \mathrm{HI}, \mathrm{QI}, \mathrm{BI}, \mathrm{S} 1+\mathrm{S} 2, \mathrm{~S} 1, \mathrm{~S} 2$, QI, TOC & Norgate et al., 1999 \\
\hline $\mathrm{k}$ & VH & $1 \sim 403$ & $\%$ Ro, $\operatorname{Tmax}\left({ }^{\circ} \mathrm{C}\right), \mathrm{HI}, \mathrm{QI}, \mathrm{BI}, \mathrm{S} 1+\mathrm{S} 2, \mathrm{~S} 1, \mathrm{~S} 2$, QI, TOC & Veld et al., 1993 \\
\hline 1 & MG & $1 \sim 27$ & $\%$ Ro, Tmax $\left({ }^{\circ} \mathrm{C}\right), \mathrm{HI}, \mathrm{QI}, \mathrm{BI}, \mathrm{PI}, \mathrm{S} 2, \mathrm{TOC}, \mathrm{S} 1+\mathrm{S} 2, \mathrm{~S} 1$ & Wang , 1998 \\
\hline $\mathrm{m}$ & MS & $1 \sim 24$ & $\% \operatorname{Ro}, \operatorname{Tmax}\left({ }^{\circ} \mathrm{C}\right), \mathrm{HI}, \mathrm{QI}, \mathrm{BI}, \mathrm{PI}, \mathrm{S} 2, \mathrm{TOC}, \mathrm{S} 1+\mathrm{S} 2, \mathrm{~S} 1$ & Xiao et al., 1996 \\
\hline $\mathrm{n}$ & MT & $1 \sim 16$ & $\%$ Ro, $\operatorname{Tmax}\left({ }^{\circ} \mathrm{C}\right), \mathrm{HI}, \mathrm{QI}, \mathrm{BI}, \mathrm{PI}, \mathrm{S} 2, \mathrm{TOC}, \mathrm{S} 1+\mathrm{S} 2, \mathrm{~S} 1$ & Xiao, 1997 \\
\hline o & TU & $1 \sim 12$ & $\%$ Ro, Tmax $\left({ }^{\circ} \mathrm{C}\right), \mathrm{HI}, \mathrm{S} 2, \mathrm{TOC}, \mathrm{S} 1+\mathrm{S} 2, \mathrm{~S} 1, \mathrm{QI}, \mathrm{BI}, \mathrm{PI}$ & $\mathrm{Wu}$, et al.2003 \\
\hline $\mathrm{p}$ & MU & $1 \sim 13$ & $\%$ Ro, Tmax $\left({ }^{\circ} \mathrm{C}\right), \mathrm{HI}, \mathrm{S} 1, \mathrm{~S} 1+\mathrm{S} 2, \mathrm{~S} 1, \mathrm{QI}, \mathrm{BI}, \mathrm{PI}, \mathrm{TOC}$ & Liu, et al., 2000 \\
\hline $\mathrm{q}$ & $\mathrm{TK}$ & $1 \sim 25$ & $\% \operatorname{Ro}, \operatorname{Tmax}\left({ }^{\circ} \mathrm{C}\right), \mathrm{HI}, \mathrm{QI}, \mathrm{BI}, \mathrm{PI}, \mathrm{S} 2, \mathrm{TOC}, \mathrm{S} 1+\mathrm{S} 2, \mathrm{~S} 1$ & Chiu et al., 1993 \\
\hline $\mathrm{r}$ & $\mathrm{TC}$ & $1 \sim 41$ & $\%$ Ro, Tmax $\left({ }^{\circ} \mathrm{C}\right), \mathrm{HI}, \mathrm{QI}, \mathrm{BI}, \mathrm{PI}, \mathrm{S} 2, \mathrm{TOC}, \mathrm{S} 1+\mathrm{S} 2, \mathrm{~S} 1$ & Chiu et al., 1996 \\
\hline $\mathrm{s}$ & TW & $1 \sim 48$ & $\%$ Ro, Tmax $\left({ }^{\circ} \mathrm{C}\right), \mathrm{HI}, \mathrm{QI}, \mathrm{BI}, \mathrm{PI}, \mathrm{S} 2, \mathrm{TOC}, \mathrm{S} 1+\mathrm{S} 2, \mathrm{~S} 1$ & \\
\hline $\mathrm{t}$ & ML & $1 \sim 59$ & $\%$ Ro, Tmax $\left({ }^{\circ} \mathrm{C}\right), \mathrm{HI}, \mathrm{QI}, \mathrm{BI}, \mathrm{PI}, \mathrm{S} 2, \mathrm{TOC}, \mathrm{S} 1+\mathrm{S} 2, \mathrm{~S} 1$ & \\
\hline $\mathrm{u}$ & $\mathrm{AU}$ & $1 \sim 13$ & $\%$ Ro, Tmax $\left({ }^{\circ} \mathrm{C}\right), \mathrm{HI}, \mathrm{QI}, \mathrm{BI}, \mathrm{PI}, \mathrm{S} 2, \mathrm{TOC}, \mathrm{S} 1+\mathrm{S} 2, \mathrm{~S} 1$ & \\
\hline
\end{tabular}

$※ 1$. Sample data of $\mathrm{a} \sim \mathrm{r}$ from the literature(Notes)

2. Sample data of $\mathrm{s} \sim \mathrm{u}$ were detected in this study

3. $\mathrm{HI}(\mathrm{S} 1 / \mathrm{TOC}), \mathrm{QI}([\mathrm{S} 1+\mathrm{S} 2] / \mathrm{TOC}), \mathrm{BI}(\mathrm{S} 1 / \mathrm{TOC}), \mathrm{PI}(\mathrm{S} 1 /[\mathrm{S} 1+\mathrm{S} 2])$

4. The dataset of 1140 samples contain 3 parameters (\%Ro, Tmax, HI)

5. The dataset of 608 samples contain 10 parameters (\%Ro, Tmax, HI, QI, BI, PI, S2, TOC, S1+S2, S1) 


\subsection{Kruskal-Waillis Test}

$$
K-W=\frac{12}{N(N+1)} \sum_{i}^{k} n_{i}\left(\bar{R}_{i}-\bar{R}\right)^{2}
$$

where $\bar{R}$ represents mean rank, $n_{i}$ represents the observation number of i group, $k$ represents the number of groups, and $N$ represent the total observation number of all groups.

If $p$ (probability) $>\alpha(0.05$, significance level), accept null hypothesis (Ho).

\subsection{2-Independent T-Test}

The 2-independentT-tests used here evaluates the probability that the mean value of a particular parameter exhibited by two data sets $\left(\bar{x}_{1}\right.$ and $\left.\bar{x}_{2}\right)$. -The t-statistic is obtained using the following equation- : $t=\frac{\overline{x_{1}}-\overline{x_{2}}}{\sqrt{\frac{S_{p}^{2}}{n_{1}}-\frac{S_{p}^{2}}{n_{2}}}}$, where $\bar{x}_{1} 、 \bar{x}_{2}$ represent the mean value,

$$
S_{p}^{2}=\frac{\left(n_{1}-1\right) S_{1}^{2}+\left(n_{2}-1\right) S_{2}^{2}}{n_{1}+n_{2}-1}
$$

where $n_{1} 、 n_{2}$ represent the number of measurements and $S_{1}$ 、 $S_{2}$ represent the standard deviation.

If $p$ (probability) $>\alpha(0.05$, significance level), accept null hypothesis (Ho).

Chi-squared $\left(x^{2}\right)$ statistics were used to assess the normality of the distribution of values in the data setfor a particular parameter. $x^{2}=\sum_{i=1}^{r} \frac{\left(n_{i}-e_{i}\right)^{2}}{e_{i}}$

Where $r$ is the number of categories, $n_{i}$ are the observed frequencies and $e_{i}$ are the theoretical frequencies.

\subsection{K-Independence Samples Test}

$$
x^{2}=\sum_{i=1}^{2} \sum_{j=1}^{k} \frac{\left(O_{i j}-E_{i j}\right)^{2}}{E_{i j}}
$$

where $O_{i j}$ represents observation number, i is number of row, $\mathrm{j}$ is number of column, and $E_{i j}$ represents expectation number, $i$ is number of row,$j$ is number of column.

If $p$ (probability) $>\alpha(0.05$, significance level), accept null hypothesis (Ho).

\section{Results and Discussion}

\subsection{Grey Relational Analysis}

The results from statistical analysis of the all parameters data for all samples in this research project, not only be executed a linear regression, curve regression between any two parameters, and multivariate regression, but also be carried on the forecast of grey correlation grade of grey theory (include grey relational generating of Chang's, Effect, Hsia's, and Lin's (Nominal-the-better-:Ro\%; Larger-the-better-: Tmax, HI, QI, BI, S2, S1+ S2, S1; smaller-the-better-: TOC, PI; Tables 2-5) and globalization grey relational grade; Table 6). So far, achieve approximately consistent results from two modes predictive analysis. Petroleum potential can be divided into four different parts based on the cross-plot of HI vs. \%Ro. The highest petroleum potential is located in the second part with $\%$ Ro $=0.6-1.0 \%, \mathrm{~T}_{\max }=430-450^{\circ} \mathrm{C}, \mathrm{HI}>100$, and QI $>120$. Oil generation potential is rapidly exhausted in the third part with $\%$ Ro $>1.0 \%$. This result is in accordance with the regression curve of $\mathrm{HI}$ and QI with \%Ro based on 97 samples with $\% \mathrm{Ro}=1.0 \sim 5.6 \%$. The exponential equation of regression can thus be achieved: $H I=994.8 e^{-1.7 R o}$ and $Q I=1646.2 e^{-2.0 R o} \quad\left(\mathrm{R}^{2}=0.72\right)$.

Table 2. The results of Chang's grey relational generating for the data of all parameters (focus the data from $R o \%=1.0$ to $R o \%=5.6$ )

\begin{tabular}{lllllllll}
\hline Ro\% & Tmax & HI & QI & BI & S2 & S1+S2 & S1 & TOC \\
\hline 0.933 & 0.926 & 0.193 & 0.207 & 0.126 & 0.009 & 0.010 & 0.016 & -28.583 \\
0.933 & 0.930 & 0.177 & 0.187 & 0.082 & 0.002 & 0.002 & 0.002 & -4.917 \\
0.933 & 0.915 & 0.125 & 0.135 & 0.078 & 0.003 & 0.003 & 0.004 & -11.167 \\
0.933 & 0.926 & 0.154 & 0.168 & 0.128 & 0.001 & 0.001 & 0.001 & -0.667 \\
0.933 & 0.911 & 0.381 & 0.392 & 0.087 & 0.044 & 0.045 & 0.026 & -72.417 \\
0.933 & 0.922 & 0.041 & 0.041 & 0.000 & 0.000 & 0.000 & 0.000 & -2.500 \\
0.933 & 0.937 & 0.305 & 0.322 & 0.155 & 0.028 & 0.029 & 0.037 & -56.333 \\
0.933 & 0.930 & 0.061 & 0.125 & 0.664 & 0.000 & 0.001 & 0.010 & -1.583 \\
0.933 & 0.932 & 0.085 & 0.110 & 0.260 & 0.001 & 0.001 & 0.006 & -3.667 \\
\hline
\end{tabular}


Table 3. The results of Effect grey relational generating for the data of all parameters (focus the data from $\mathrm{Ro} \%=0.55$ to $\mathrm{Ro} \%=1.02$ )

\begin{tabular}{|c|c|c|c|c|c|c|c|c|}
\hline Ro\% & Tmax & HI & QI & BI & S2 & $\mathrm{S} 1+\mathrm{S} 2$ & S1 & TOC \\
\hline 0.933 & 0.945 & 0.428 & 0.467 & 0.368 & 0.010 & 0.011 & 0.023 & 0.065 \\
\hline 0.933 & 0.926 & 0.193 & 0.207 & 0.126 & 0.009 & 0.010 & 0.016 & 0.033 \\
\hline 0.933 & 0.930 & 0.177 & 0.187 & 0.082 & 0.002 & 0.002 & 0.002 & 0.145 \\
\hline 0.933 & 0.930 & 0.291 & 0.305 & 0.128 & 0.088 & 0.092 & 0.101 & 0.005 \\
\hline 0.933 & 0.915 & 0.125 & 0.135 & 0.078 & 0.003 & 0.003 & 0.004 & 0.076 \\
\hline 0.933 & 0.926 & 0.154 & 0.168 & 0.128 & 0.001 & 0.001 & 0.001 & 0.375 \\
\hline 0.938 & 0.937 & 0.305 & 0.322 & 0.155 & 0.028 & 0.029 & 0.037 & 0.017 \\
\hline 0.938 & 0.930 & 0.061 & 0.125 & 0.664 & 0.000 & 0.001 & 0.010 & 0.279 \\
\hline
\end{tabular}

Table 4. The results of Hsia' grey relational generating for the data of all parameters (focus the data from Ro $\%=0.17$ to Ro $\%=5.6$ )

\begin{tabular}{|c|c|c|c|c|c|c|c|c|c|}
\hline Ro\% & Tmax & HI & QI & BI & S2 & $\mathrm{S} 1+\mathrm{S} 2$ & S1 & TOC & PI \\
\hline 0.920 & 0.507 & 0.353 & 0.370 & 0.097 & 0.295 & 0.302 & 0.207 & 0.258 & 0.952 \\
\hline 0.920 & 0.452 & 0.299 & 0.322 & 0.164 & 0.312 & 0.327 & 0.435 & 0.078 & 0.921 \\
\hline 0.920 & 0.438 & 0.347 & 0.360 & 0.057 & 0.328 & 0.332 & 0.138 & 0.163 & 0.968 \\
\hline 0.920 & 0.438 & 0.353 & 0.375 & 0.147 & 0.243 & 0.252 & 0.258 & 0.390 & 0.937 \\
\hline 0.920 & 0.480 & 0.314 & 0.325 & 0.032 & 0.334 & 0.336 & 0.088 & 0.060 & 0.984 \\
\hline 0.920 & 0.521 & 0.216 & 0.235 & 0.098 & 0.020 & 0.021 & 0.023 & 0.921 & 0.937 \\
\hline 0.920 & 0.575 & 0.086 & 0.141 & 0.479 & 0.001 & 0.001 & 0.012 & 0.993 & 0.492 \\
\hline 0.920 & 0.616 & 0.343 & 0.371 & 0.207 & 0.036 & 0.038 & 0.056 & 0.908 & 0.921 \\
\hline
\end{tabular}

Table 5. The results of Lin's grey relational generating for the data of all parameters (focus the data from $R o \%=0.17$ to Ro\%=0.6)

\begin{tabular}{|c|c|c|c|c|c|c|c|c|c|}
\hline Ro\% & Tmax & HI & QI & BI & S2 & $\mathrm{S} 1+\mathrm{S} 2$ & S1 & TOC & PI \\
\hline 0.922 & 0.300 & 0.149 & 0.187 & 0.156 & 0.140 & 0.167 & 0.960 & 0.020 & 0.735 \\
\hline 0.922 & 0.415 & 0.061 & 0.074 & 0.032 & 0.069 & 0.078 & 0.229 & 0.005 & 0.819 \\
\hline 0.922 & 0.397 & 0.084 & 0.099 & 0.027 & 0.009 & 0.009 & 0.018 & 0.520 & 0.848 \\
\hline 0.929 & 0.331 & 0.003 & 0.004 & 0.005 & 0.000 & 0.000 & 0.000 & 0.990 & 0.681 \\
\hline 0.929 & 0.271 & 0.046 & 0.072 & 0.223 & 0.001 & 0.002 & 0.043 & 0.722 & 0.533 \\
\hline 0.929 & 0.192 & 0.278 & 0.319 & 0.100 & 0.014 & 0.015 & 0.032 & 0.645 & 0.848 \\
\hline 0.929 & 0.204 & 0.311 & 0.363 & 0.156 & 0.299 & 0.339 & 1.000 & 0.015 & 0.819 \\
\hline 0.929 & 0.204 & 0.138 & 0.150 & 0.007 & 0.092 & 0.096 & 0.032 & 0.075 & 0.938 \\
\hline 0.929 & 0.331 & 0.098 & 0.111 & 0.019 & 0.092 & 0.100 & 0.116 & 0.020 & 0.877 \\
\hline
\end{tabular}

Table 6. The results of Globalization grey relational grade for the data of all parameters (focus the data " from Ro\% $\%=0.5$ to Ro $\%=2.2$ ”)

\begin{tabular}{|c|c|c|c|c|}
\hline & Hsia's & Nagai's & Wen's & Wu's \\
\hline \multirow{20}{*}{ Eigenvector } & 0.0984 & 0.1148 & 0.0983 & 0.0916 \\
\hline & 0.0909 & 0.1134 & 0.0922 & 0.0855 \\
\hline & 0.0948 & 0.1148 & 0.0953 & 0.0861 \\
\hline & 0.0958 & 0.1172 & 0.0962 & 0.0962 \\
\hline & 0.0954 & 0.1062 & 0.0959 & 0.0959 \\
\hline & 0.0998 & 0.1040 & 0.0993 & 0.1006 \\
\hline & 0.0982 & 0.1114 & 0.0981 & 0.1000 \\
\hline & 0.0998 & 0.1169 & 0.0993 & 0.1006 \\
\hline & 0.0933 & 0.1104 & 0.0943 & 0.0931 \\
\hline & 0.0999 & 0.1084 & 0.0995 & 0.1008 \\
\hline & 0.0989 & 0.1017 & 0.0987 & 0.0996 \\
\hline & 0.0985 & 0.1045 & 0.0983 & 0.0994 \\
\hline & 0.0999 & 0.0963 & 0.0994 & 0.1001 \\
\hline & 0.0997 & 0.1115 & 0.0993 & 0.1006 \\
\hline & 0.0958 & 0.1115 & 0.0962 & 0.0959 \\
\hline & 0.0977 & 0.1176 & 0.0977 & 0.0996 \\
\hline & 0.0988 & 0.1152 & 0.0985 & 0.0994 \\
\hline & 0.0969 & 0.1097 & 0.097 & 0.0982 \\
\hline & 0.0967 & 0.1081 & 0.0968 & 0.0986 \\
\hline & 0.0937 & 0.1127 & 0.0944 & 0.0863 \\
\hline Maximum Eigenvalue & 96.7423 & 59.8616 & 97.6133 & 91.8172 \\
\hline
\end{tabular}




\subsection{Hierarchical Cluster Analysis of HI, QI}

A vitrinite reflectance (\%Ro) ranged from $0.5-0.55$ to 1.3 , $0.5-0.7$ to 1.3 or $0.5-0.6$ to $1.3-1.35$ for the conventional "oil window" was proposed by Petersen (2002), Teichmuller (1993), Vassoevich et al. (1974), Tissot and Welte (1984), and Hunt (1996). Q mode hierarchical cluster analysis for the dataset of 608 samples confirmed that 61 data samples with all ten parameters belong to the same cluster, numbering from $2 \sim 14$ with $0.5 \leqq \% \mathrm{Ro} \leqq 1.0, \mathrm{~S} 2<2$, and $\mathrm{HI}<80$. In addition, the others 41 data samples with ten parameters are in a different group with HI $>380$. They show higher dispersion than those with lower HI values. Peters and Cassa (1994) stated that the source rock has poor petroleum potential if the organic material has $0.5 \leqq \% \mathrm{Ro} \leqq 1.0, \mathrm{~S} 2<2$, and $\mathrm{HI}<80$. Therefore, the 102 data were removed from the cross-plots (HI vs. \%Ro, QI vs. \%Ro, BI vs. \%Ro, HI vs. Tmax, QI vs. Tmax, BI vs. Tmax) for dataset of 608 samples, after deleting 102 data from dataset of 608 samples, another dataset of 506 samples could be obtained. Nonparametric tests ( 2 and $\mathrm{k}$ independent samples) between the datasets of 608 and 506 samples confirm that the distribution of values from respective parameters except TOC exhibit no significant difference $(p>0.05$, Table $7 \mathrm{a}, 7 \mathrm{~b})$. Nonparametric tests $(\mathrm{k}$ independent samples) among the datasets of 1140,608 , and 506 samples, showed that there was no significant difference $(p>0.05$, Table $7 \mathrm{c})$ in the distribution of $\mathrm{HI}$ values. The distribution of the HI value for all of the datasets remains constant with increasing thermal maturity.

After conducting a Pearson's correlation analysis for datasets of 608 and 506 samples, exhibited same results and they had high correlation about the couple of parameters (\%Ro vs. Tmax, HI vs. QI, TOC vs. [S1+S2], S2vs. [S1+S2], S2 vs. TOC; cf. Table 8a). So they were obtained again the evolution in the $\mathrm{HI}$ with increasing thermal maturity for a large worldwide datasets of 608, and 506 samples (Figures 1 and 2), and the evolution in the total generation (QI) with increasing maturity for the worldwide datasets of 608 and 506 samples (Figures3 and 4). From the results of Pearson's correlation analysis (Table 8b), during $\mathrm{Ro}=0.17 \sim 0.6 \%$ rise up to $\% \mathrm{Ro}=0.61 \sim 1.0$, declining the correlativity for $\mathrm{HI}$ and $\mathrm{QI}$ with BI from medium to low while BI increase with thermal maturity until the \%Ro up to $\sim 0.75 \%$ Ro (Figures $5-7$ ). On the other hand, during $\mathrm{Ro}=0.17 \sim 1.0 \%$ rise up to $1.0 \sim 5.6 \%$, the correlation for $\mathrm{HI}$ and QI with \%Ro increased, with correlative coefficient up to $r=-0.72$ (Table $8 \mathrm{c}$ ). They show clearly the apex of the upper and lower limit of the HI and QI band from the cross-plots (HI vs. \%Ro, QI vs. \%Ro, HI vs. T max, QI vs. $\mathrm{T}$ max) for the dataset of 506 samples. From these cross-plots, we can define more definitely to the lines of maximum $\mathrm{HI}$ and QI from $\sim 0.6$ to $\sim 1.0 \%$ Ro or from $\sim 430$ to $\sim 450^{\circ} \mathrm{C}$, which in accordance with the results of descriptive analysis for the mean value of respective parameter in the interval of \%Ro span. The parameters (HI, QI) have the highest mean value with increasing thermal maturity at the $\sim 0.6 \%$ Ro (within $0.5-0.7 \%$ Ro ) and $\sim 1.0 \%$ Ro (within $0.9-1.1 \% \mathrm{Ro}$ ), $\sim 430^{\circ} \mathrm{C}$ Tmax (within $425-435^{\circ} \mathrm{C} \mathrm{Tmax}$ ) and $\sim 450^{\circ} \mathrm{C} \mathrm{Tmax}$ (within $442-460^{\circ} \mathrm{C}$ Tmax) (Table 9).
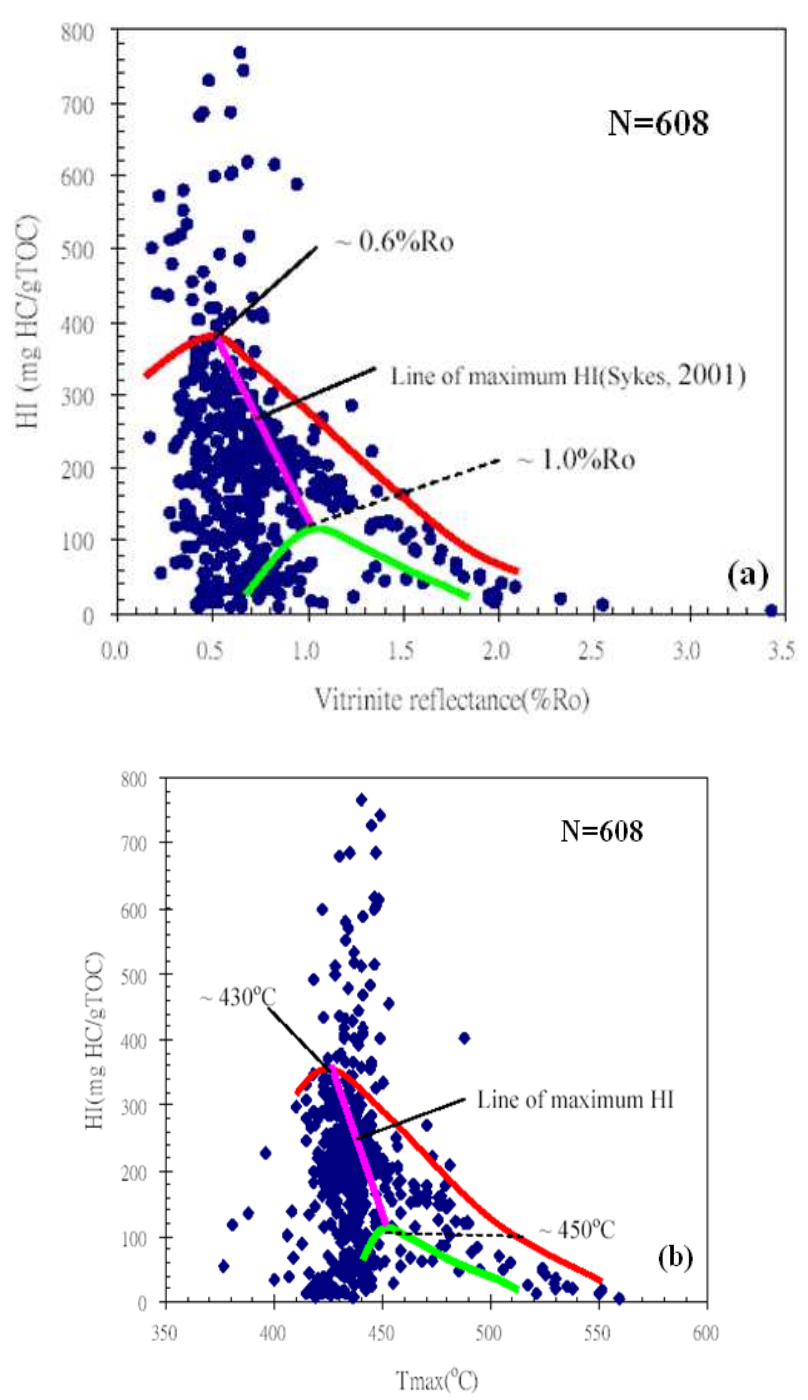

Fig. 1. The evolution in the HI with increasing thermal maturity for a large worldwide dataset of 608 samples: (a) HI vs. \%Ro; (b)HI vs. Tmax. The sample data define an HI band that narrows with increasing maturity. A line of maximum HI can be confirmed from $\sim 0.6$ to $1.0 \%$ Ro or from $\sim 430$ to $450^{\circ} \mathrm{C}$.

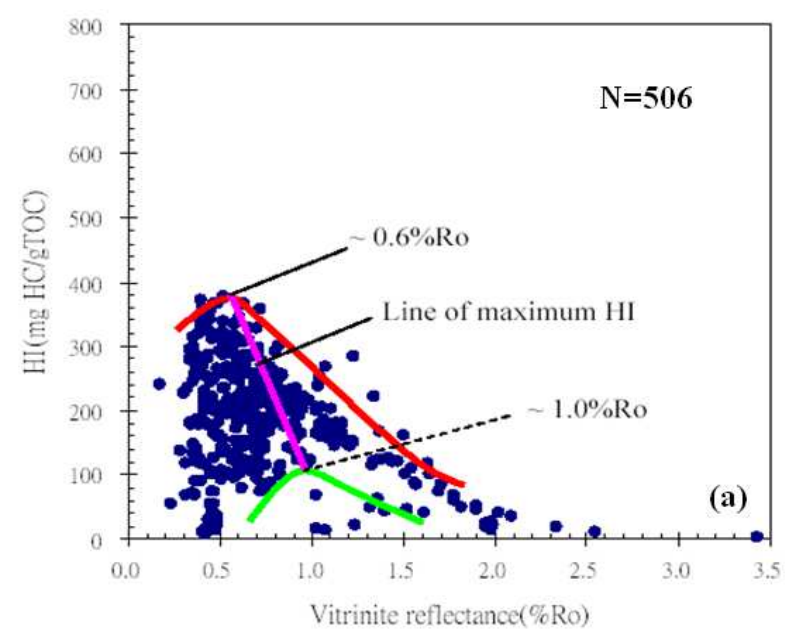




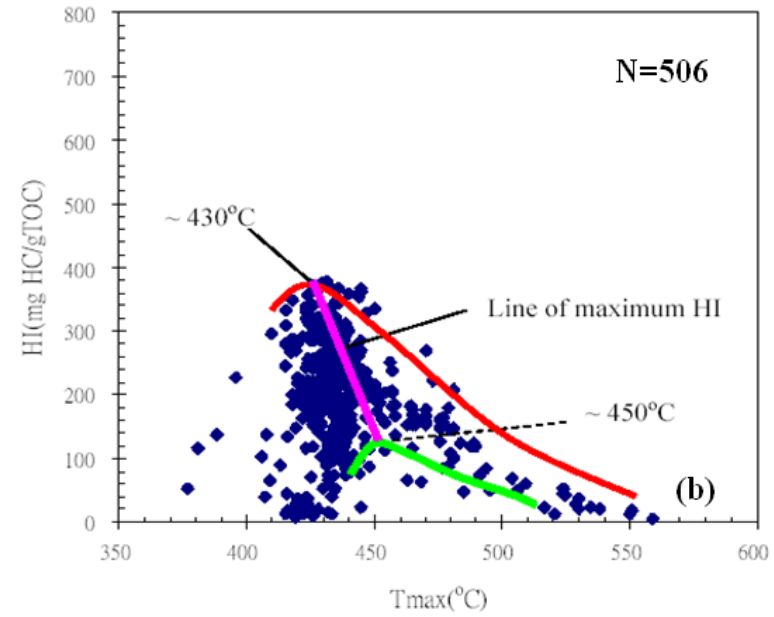

Fig. 2. The evolution in the HI with increasing thermal maturity for a large worldwide dataset of 506 samples: (a)HI vs. \%Ro; (b)HI vs. Tmax. After deleting 102 data from dataset of 608 samples, can present very clearly the upper and lower limit of the HI band. From this fig., We can define more definitely to a line of maximum HI from $\sim 0.6$ to $1.0 \%$ Ro or from $\sim 430$ to $450^{\circ} \mathrm{C}$.
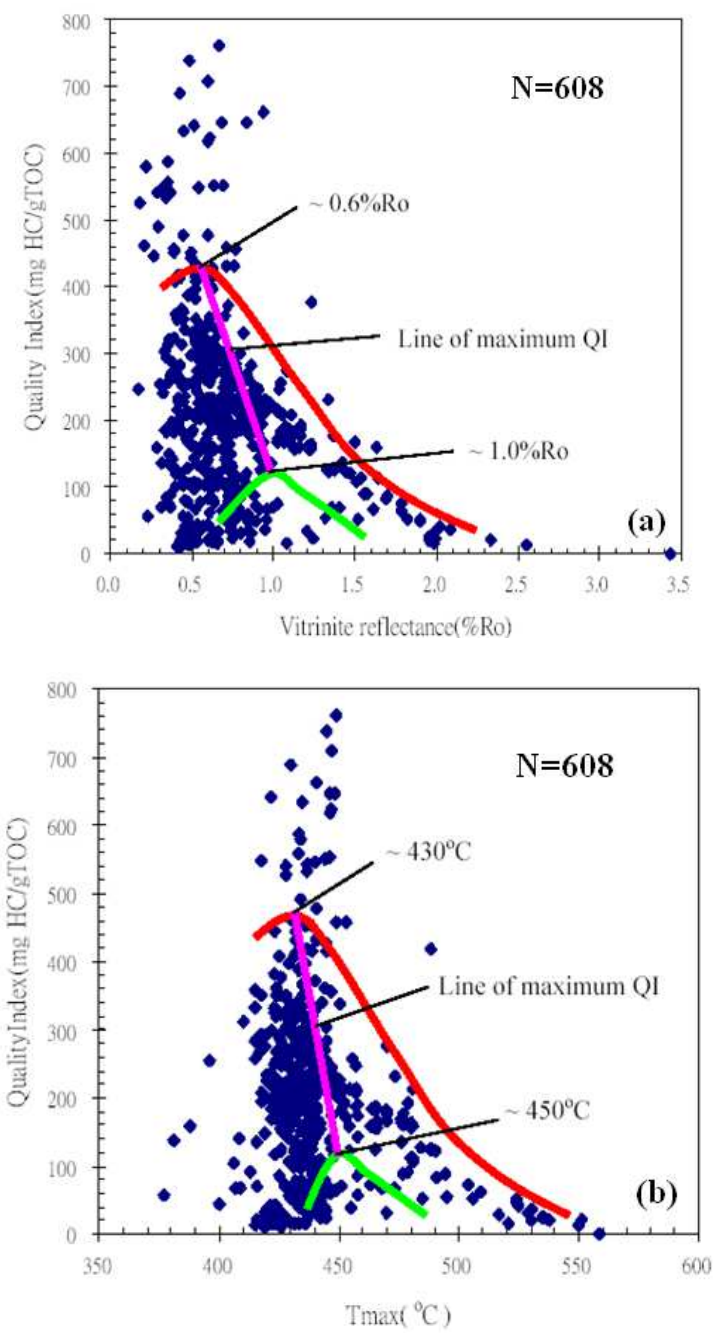

Fig. 3. The evolution in the total generation (QI) with increasing maturity for the worldwide dataset of 608 samples: (a) QI vs. \%Ro; (b) QI vs. Tmax. The decline in QI indicates the onset of initial oil expulsion.
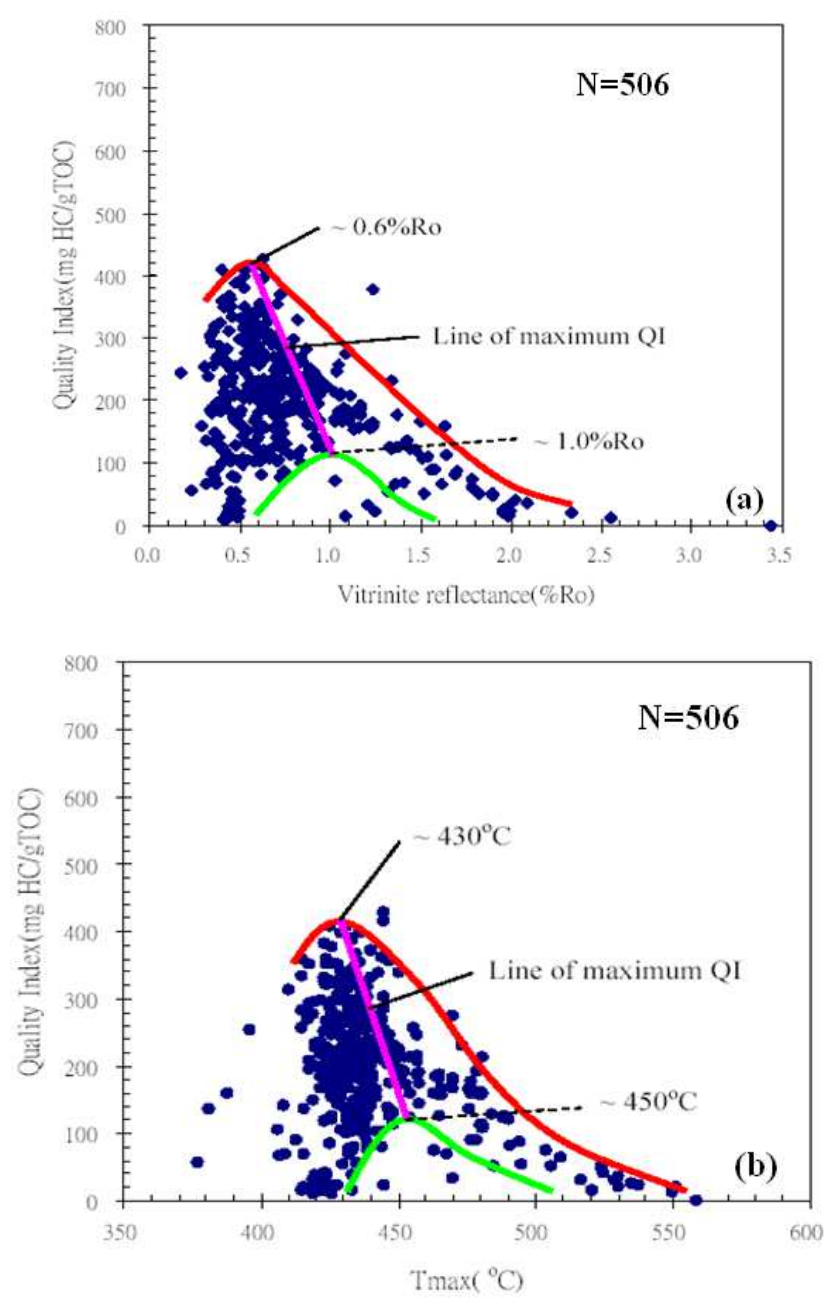

Fig. 4. The evolution in the QI with increasing thermal maturity for a large worldwide dataset of 506 samples: (a)QI vs. \%Ro; (b)QI vs. Tmax. After deleting 102 datas from dataset of 608 samples, can present very clearly the upper and lower limit of the QI band. From this fig., We can define more definitely to a line of maximum HI from 0.6 to $1.0 \%$ Ro or from $\sim 430$ to $450^{\circ} \mathrm{C}$.

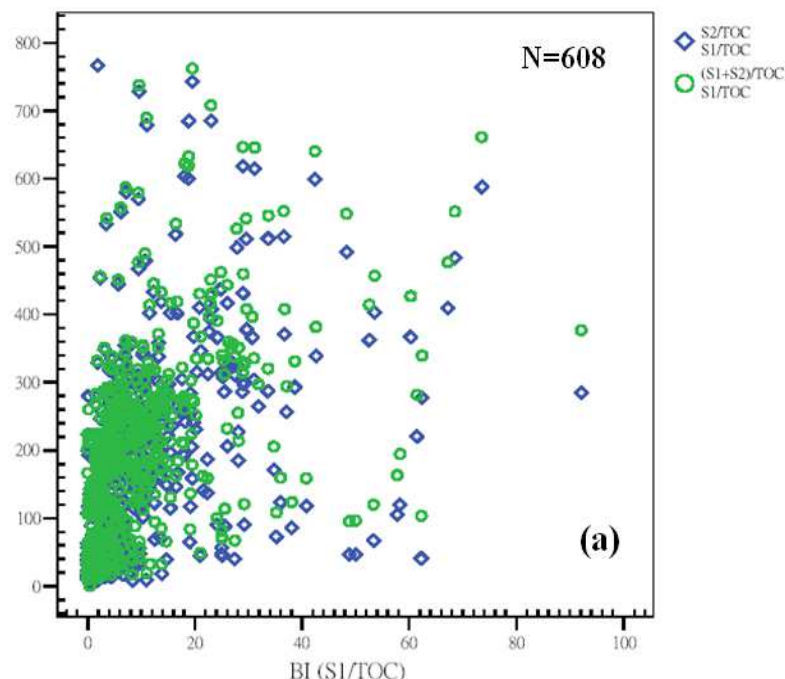




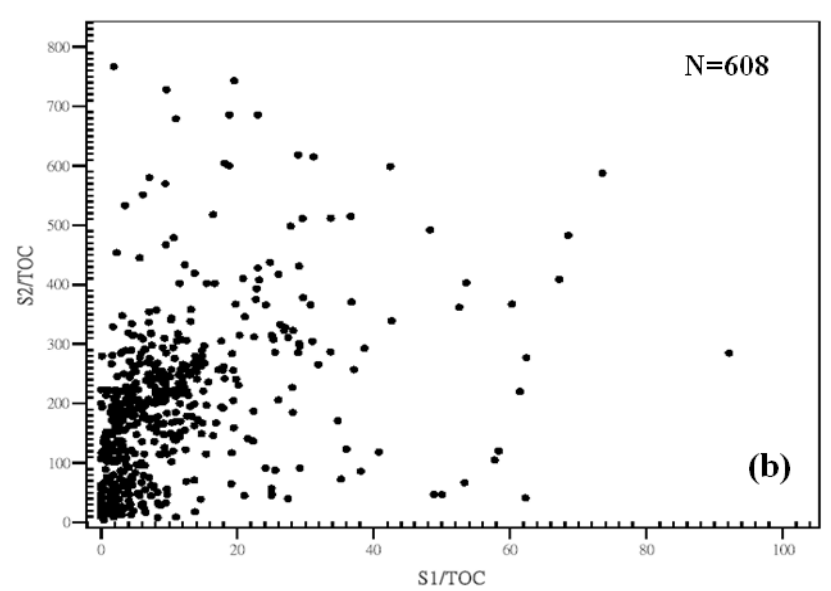

Fig. 5. (a) Plot of HI and QI (Y-axial) vs. BI; (b) Plot of HI vs. BI for dataset of 608 samples.

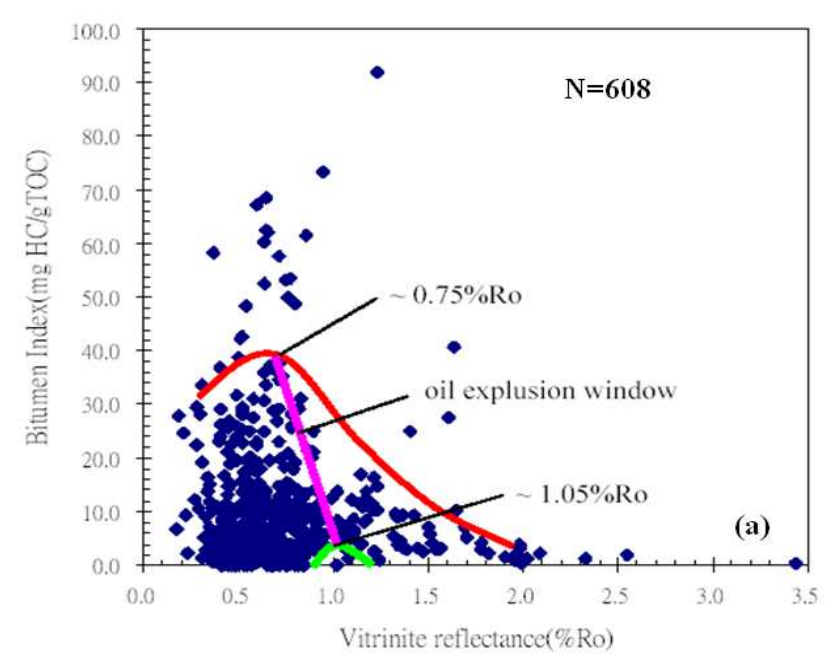

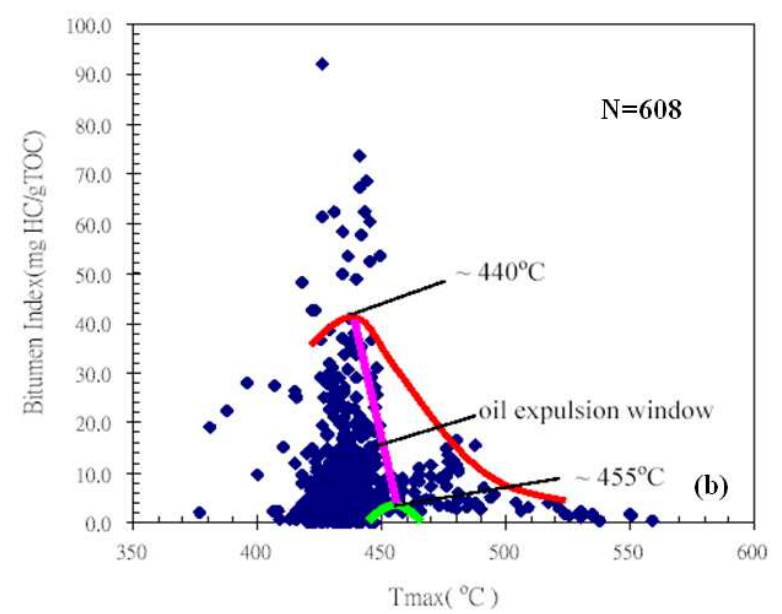

Fig. 6. (a) BI vs. \%Ro and (b) BI vs. Tmax for the worldwide dataset of 608 samples. The majority of the samples confirm a BI band that illustrates the "oil expulsion window". The line between $\sim 0.75$ and $\sim 1.05 \%$ Ro or 440 and $455^{\circ} \mathrm{C}$ defines the start of the effective oil window.

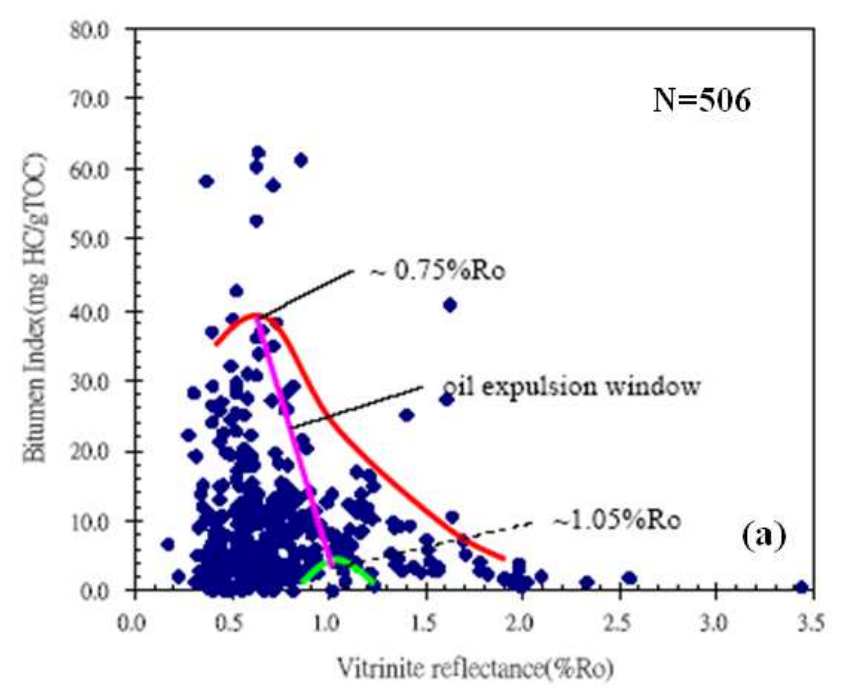

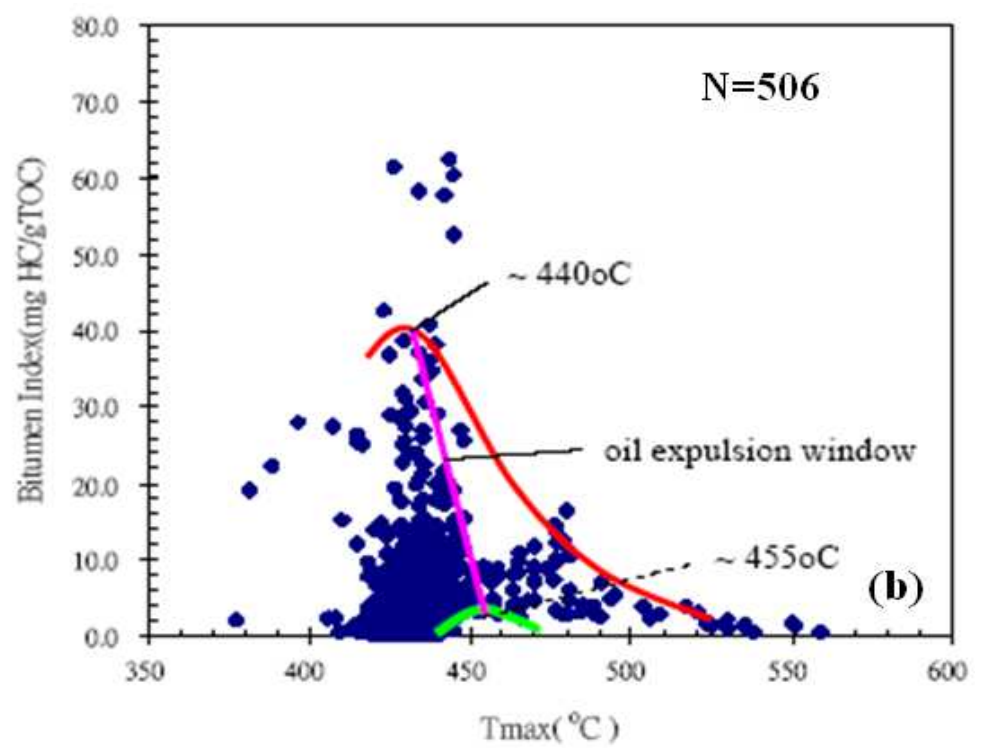

Fig. 7. (a) BI vs. \%Ro and (b) BI vs. Tmax for the worldwide dataset of 506 samples. The majority of the samples confirm a BI band that illustrates the "oil expulsion window". The line between $\sim 0.75$ and $\sim 1.05 \%$ Ro or 440 and $455^{\circ} \mathrm{C}$ defines the start of the effective oil window. 
Table 7. The large amount of data allows statistically significant differences between the parameters from different datasets to be established.

\begin{tabular}{|c|c|c|c|c|c|c|c|c|c|c|c|}
\hline \multirow{2}{*}{ (a)Test } & & \multicolumn{10}{|c|}{ parameters } \\
\hline & & $\%$ Ro & Tmax & HI & QI & BI & PI & S2 & TOC & $\mathrm{S} 1+\mathrm{S} 2$ & S1 \\
\hline A & Sig & 0.58 & 0.18 & 1.00 & 1.00 & 0.96 & 0.00 & 0.97 & 0.63 & 0.98 & 0.49 \\
\hline B & Sig & 0.95 & 0.99 & 0.05 & 0.08 & 0.87 & 0.36 & 0.05 & 0.04 & 0.05 & 0.16 \\
\hline $\mathrm{C}$ & Sig & 0.65 & 0.64 & 0.61 & 0.59 & 0.33 & 0.09 & 0.03 & 0.01 & 0.03 & 0.05 \\
\hline$※$ & $\begin{array}{l}\text { 1. A: } \\
\text { 2. Si } \\
\text { 3. If }\end{array}$ & $\begin{array}{l}\text { esTest; } \\
\text { value (a) } \\
\text { accept } r\end{array}$ & $\begin{array}{l}\text { vo-Samp } \\
\text { panying } \\
\text { lypothesi }\end{array}$ & $\begin{array}{l}\operatorname{lmogo} \\
\text { ability; } \\
\text { ). It re }\end{array}$ & $\begin{array}{l}\text { nirnov } \\
\text { icance } \\
\text { ts no si }\end{array}$ & $\begin{array}{l}\text { : Man } \\
=0.05 \text { ) } \\
\text { ant diff }\end{array}$ & itney & & & & \\
\hline
\end{tabular}

\begin{tabular}{|c|c|c|c|c|c|c|c|c|}
\hline \multirow{2}{*}{ (b)Test } & & \multicolumn{7}{|c|}{ parameters } \\
\hline & & $\%$ Ro & Tmax & HI & QI & BI & PI & S1 \\
\hline \multirow{4}{*}{ D } & (1) $\chi^{2}$ & 0.05 & 0.47 & 0.39 & 0.47 & 0.49 & 2.13 & 1.93 \\
\hline & Sig. & 0.82 & 0.49 & 0.53 & 0.49 & 0.48 & 0.14 & 0.16 \\
\hline & (2) $\chi^{2}$ & 0.03 & 0.39 & 0.32 & 0.38 & 0.40 & 1.94 & 1.76 \\
\hline & Sig. & 0.87 & 0.53 & 0.57 & 0.53 & 0.53 & 0.16 & 0.18 \\
\hline \multirow{2}{*}{ E } & (1) $\chi^{2}$ & 0.19 & 0.22 & 0.26 & 0.28 & 0.92 & 2.81 & 3.57 \\
\hline & Sig. & 0.65 & 0.64 & 0.61 & 0.59 & 0.33 & 0.09 & 0.06 \\
\hline $\mathrm{F}$ & Sig. & 0.660 & 0.64 & 0.61 & 0.59 & 0.34 & 0.09 & 0.06 \\
\hline \multicolumn{9}{|c|}{$\begin{array}{l}\text { 1. D: Median Test; E: Kruskal-Wallis Test; F: Jonckheere-Terpstra Test. } \\
\text { 2. (1) } \chi^{2} \text { : chi-square statistics; (2) } \chi^{2} \text { : Yales' continuity chi-square correction. }\end{array}$} \\
\hline
\end{tabular}

\begin{tabular}{|c|c|c|c|c|}
\hline \multirow{2}{*}{ (c)Tests } & & \multicolumn{3}{|c|}{ parameters } \\
\hline & & $\%$ Ro & Tmax & HI \\
\hline \multirow{2}{*}{ D } & $(1) x^{2}$ & 66.30 & 9.01 & 4.05 \\
\hline & Sig. & 0.00 & 0.01 & 0.13 \\
\hline \multirow{2}{*}{ E } & $(1) x^{2}$ & 56.79 & 18.53 & 0.61 \\
\hline & Sig. & 0.00 & 0.00 & 0.73 \\
\hline $\mathrm{F}$ & Sig. & 0.00 & 0.00 & 0.60 \\
\hline \multicolumn{5}{|c|}{$\begin{array}{l}\text { 1. D: Median Test; E: Kruskal-Wallis Test; F: Jonckheere-Terpstra Test. } \\
\text { 2. } \chi^{2} \text { : chi-square statistics. }\end{array}$} \\
\hline
\end{tabular}

\begin{tabular}{|c|c|c|c|c|c|c|c|c|c|c|c|}
\hline \multirow{2}{*}{\multicolumn{2}{|c|}{ (d)Tests }} & \multicolumn{10}{|c|}{ parameters } \\
\hline & & \%Ro & Tmax & HI & QI & BI & PI & S2 & TOC & $\mathbf{S 1 + S 2}$ & S1 \\
\hline \multirow{2}{*}{ G } & $\mathrm{t}$ & 3.01 & 4.79 & 3.64 & 4.07 & 6.02 & 6.80 & -5.28 & -9.16 & -5.10 & 0.31 \\
\hline & Sig. & 0.01 & 0.00 & 0.00 & 0.00 & 0.00 & 0.00 & 0.00 & 0.00 & 0.00 & 0.76 \\
\hline$※$ & 1. G & idepend & Samples ' & & st for e & $y$ of $M$ & & & & & \\
\hline
\end{tabular}

(a) The non-parametric tests ( 2 independent samples) for datasets of 608 and 506 samples. The distribution of data from respective parameters except TOC are not significantly different $(\mathrm{P}>\alpha)$.

(b) The non-parametric tests ( $\mathrm{K}$ independent samples) for datasets of 608 and 506 samples. The distribution of data from respective parameters are not significantly different $(\mathrm{P}>\alpha)$.

(c) The non-parametric tests ( $\mathrm{K}$ independent samples) for datasets of 1140, 608 and 506 samples show that the distribution of parameter (HI) values are not significantly difference $(\mathrm{P}>\alpha)$ between the different dataset, i.e. the distribution of $\mathrm{HI}$ in different datasets does not change with increasing thermal maturity.

(d) 2 Independent Samples T-test for TW1-48 samples and CJ1-38 samples, they exhibit the significantly different $(\mathrm{P}<\alpha)$ for type of the distribution of values from respective parameters except S1. 
Table 8. Distribution of Pearson's correlation coefficient of dataset of 608 and 506 samples

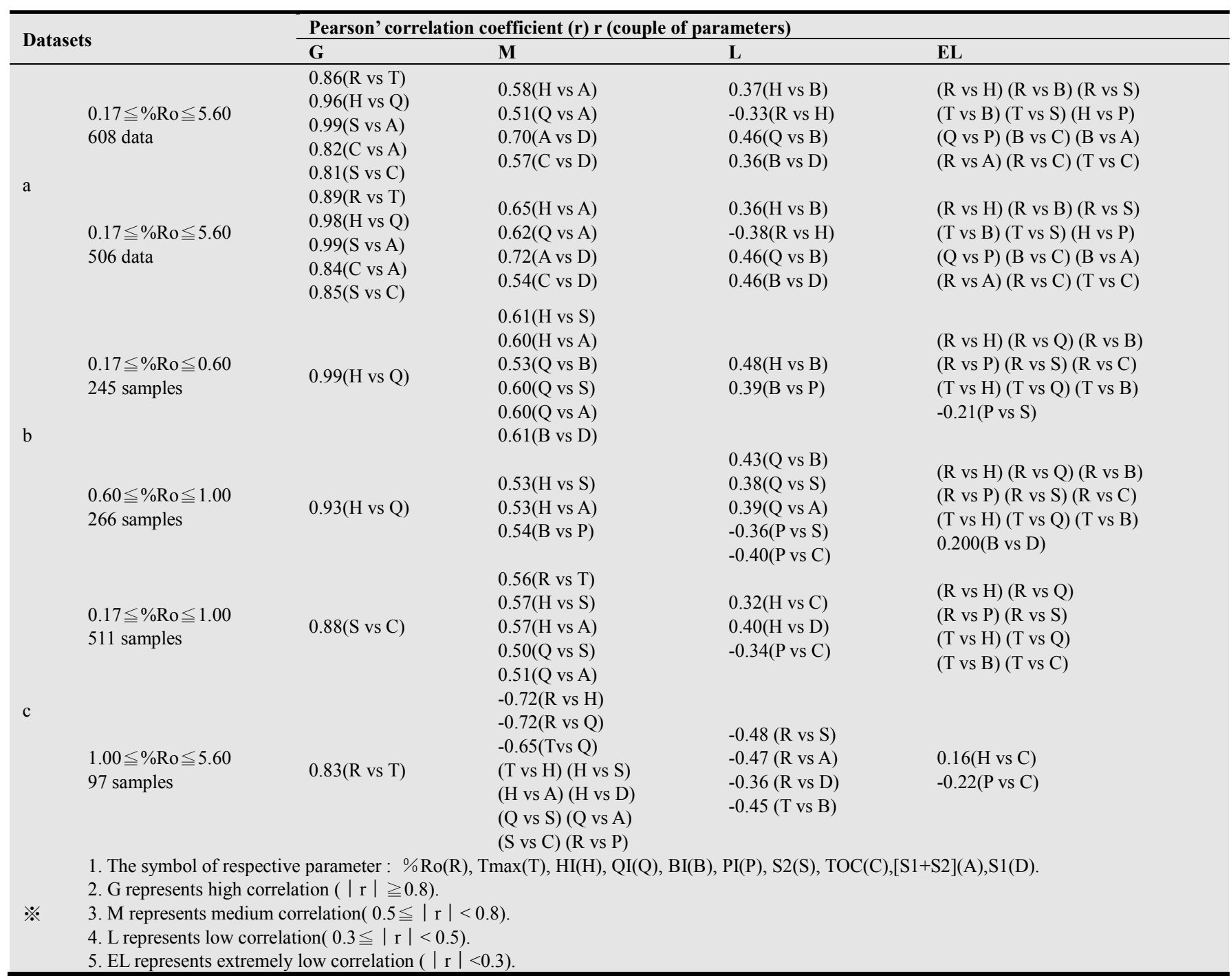

Table 9. Mean values of various parameters in different intervals of \%Ro and $\operatorname{Tmax}\left({ }^{\circ} \mathrm{C}\right)$ for datasets, with $95 \%$ confidence interval mean

\begin{tabular}{|c|c|c|c|c|c|c|c|c|c|}
\hline \multicolumn{10}{|c|}{ (a) The mean value of respective parameter in the interval of \%Ro span for dataset of 608 samples } \\
\hline Interval of \%Ro span & $\operatorname{Tmax}\left({ }^{\circ} \mathrm{C}\right)$ & HI & QI & BI & PI & S1 & S2 & $\mathbf{S 1 + S 2}$ & TOC \\
\hline $0.3<\% \operatorname{Ro} \leqq 0.4$ & 426 & 195 & 206 & 7.8 & 0.04 & 1.7 & 68 & 71 & 29 \\
\hline $0.4<\% \operatorname{Ro} \leqq 0.5$ & 429 & 202 & 207 & 7.9 & 0.05 & 3.2 & 76 & 79 & 27 \\
\hline $0.5<\% \operatorname{Ro} \leqq 0.6$ & 433 & $\underline{228}$ & $\underline{239}$ & 11.2 & 0.06 & 4.8 & $\underline{101}$ & $\underline{106}$ & 39 \\
\hline $0.6<\% \operatorname{Ro} \leqq 0.7$ & 435 & 221 & 225 & 11.6 & 0.06 & 2.9 & 89 & 93 & 36 \\
\hline $0.7<\% \operatorname{Ro} \leqq 0.8$ & 438 & 178 & 191 & $\underline{12.2}$ & $\underline{0.09}$ & 2.7 & 78 & 81 & 34 \\
\hline $0.8<\%$ Ro $\leqq 0.9$ & 440 & 176 & 186 & 10.3 & $\overline{0.08}$ & 3.1 & 89 & 91 & 42 \\
\hline $0.9<\% \operatorname{Ro} \leqq 1.0$ & 448 & 171 & 181 & 9.4 & 0.06 & 3.2 & 80 & 83 & 39 \\
\hline $1.0<\% \operatorname{Ro} \leqq 1.3$ & 460 & 166 & 177 & 9.9 & 0.05 & $\underline{4.6}$ & $\underline{94}$ & $\underline{98}$ & 56 \\
\hline $1.3<\% \operatorname{Ro} \leqq 1.7$ & 472 & 104 & 113 & 8.9 & 0.08 & 2.9 & 62 & $\overline{65}$ & 51 \\
\hline $1.7<\% \operatorname{Ro}<3.5$ & 527 & 31 & 33 & 1.8 & 0.09 & 1.0 & 20 & 21 & 59 \\
\hline \multicolumn{10}{|c|}{ (b) The mean value of respective parameter in the interval of $\operatorname{Tmax}\left({ }^{\circ} \mathrm{C}\right)$ span for dataset of 608 samples } \\
\hline Interval of $\operatorname{Tmax}\left({ }^{\circ} \mathrm{C}\right) \operatorname{span}$ & $\%$ Ro & HI & QI & BI & PI & SI & S2 & $\mathbf{S 1}+\mathbf{S} 2$ & TOC \\
\hline $377 \leqq \operatorname{Tmax} \leqq 420$ & 0.46 & 164 & 174 & 8.7 & 0.07 & 3.2 & 68 & 71 & 34 \\
\hline $420<\operatorname{Tmax} \leqq 425$ & 0.47 & 180 & 188 & 8.1 & 0.06 & 2.3 & 67 & 69 & 27 \\
\hline $425<\operatorname{Tmax} \leqq 430$ & 0.59 & $\underline{219}$ & $\underline{231}$ & 10.8 & 0.05 & 4.9 & 117 & 121 & 48 \\
\hline $430<\operatorname{Tmax} \leqq 435$ & 0.62 & $\overline{213}$ & $\overline{225}$ & 10.8 & 0.06 & 3.4 & 93 & 97 & 35 \\
\hline $435<\operatorname{Tmax} \leqq 438$ & 0.65 & 194 & 202 & 10.6 & 0.07 & 3.1 & 76 & 79 & 31 \\
\hline $438<\operatorname{Tmax} \leqq 442$ & 0.67 & 200 & 206 & 12.9 & 0.09 & 2.9 & 80 & 83 & 29 \\
\hline $442<\operatorname{Tmax} \leqq 450$ & 0.77 & 252 & 268 & 15.2 & $\overline{0.06}$ & 3.7 & 88 & 92 & 38 \\
\hline
\end{tabular}




\begin{tabular}{|c|c|c|c|c|c|c|c|c|c|}
\hline $450<\operatorname{Tmax} \leqq 460$ & 0.93 & 176 & 182 & 6.9 & 0.05 & 2.7 & 93 & 97 & 44 \\
\hline $460<\operatorname{Tmax} \leqq 500$ & $1 . .24$ & 142 & 147 & 7.2 & 0.05 & $\underline{4.7}$ & 89 & 93 & 59 \\
\hline $500<\operatorname{Tmax} \leqq 559$ & 2.06 & 31 & 33 & 1.8 & 0.09 & 0.9 & 20 & 21 & 58 \\
\hline \multicolumn{10}{|c|}{ (c)Dataset of 1140 samples. The mean value of respective parameter in the interval of $\%$ Ro and $\operatorname{Tmax}\left({ }^{\circ} \mathrm{C}\right)$ span } \\
\hline Interval of \%Ro span & $\operatorname{Tmax}\left({ }^{\circ} \mathrm{C}\right)$ & HI & \multicolumn{3}{|c|}{ Interval of $\operatorname{Tmax}\left({ }^{\circ} \mathrm{C}\right)$ span } & \multicolumn{2}{|r|}{$\%$ Ro } & \multicolumn{2}{|c|}{ HI } \\
\hline $0.3<\% \operatorname{Ro} \leqq 0.4$ & 427 & 188 & \multicolumn{3}{|c|}{$377 \leqq \operatorname{Tmax} \leqq 420$} & \multicolumn{2}{|r|}{0.45} & \multicolumn{2}{|c|}{189} \\
\hline $0.4<\% \operatorname{Ro} \leqq 0.5$ & 430 & 216 & \multicolumn{3}{|c|}{$420<\operatorname{Tmax} \leqq 425$} & \multicolumn{2}{|r|}{0.47} & \multicolumn{2}{|c|}{193} \\
\hline $0.5<\% \operatorname{Ro} \leqq 0.6$ & 434 & $\underline{244}$ & \multicolumn{3}{|c|}{$425<\operatorname{Tmax} \leqq 430$} & \multicolumn{2}{|r|}{0.56} & \multicolumn{2}{|c|}{212} \\
\hline $0.6<\% \operatorname{Ro} \leqq 0.7$ & 435 & 230 & \multicolumn{3}{|c|}{$430<\operatorname{Tmax} \leqq 435$} & \multicolumn{2}{|r|}{0.73} & \multicolumn{2}{|c|}{199} \\
\hline $0.7<\% \operatorname{Ro} \leqq 0.8$ & 437 & 181 & \multicolumn{3}{|c|}{$435<\operatorname{Tmax} \leqq 438$} & \multicolumn{2}{|r|}{0.74} & \multicolumn{2}{|c|}{201} \\
\hline $0.8<\% \operatorname{Ro} \leqq 0.9$ & 440 & 183 & \multicolumn{3}{|c|}{$438<\operatorname{Tmax} \leqq 442$} & \multicolumn{2}{|r|}{0.77} & \multicolumn{2}{|c|}{205} \\
\hline $0.9<\% \operatorname{Ro} \leqq 1.0$ & 443 & 171 & \multicolumn{3}{|c|}{$442<\operatorname{Tmax} \leqq 450$} & \multicolumn{2}{|r|}{0.82} & \multicolumn{2}{|c|}{234} \\
\hline $1.0<\% \operatorname{Ro} \leqq 1.1$ & 454 & $\underline{182}$ & \multicolumn{3}{|c|}{$450<\operatorname{Tmax} \leqq 460$} & \multicolumn{2}{|r|}{1.02} & \multicolumn{2}{|c|}{182} \\
\hline $1.1<\% \operatorname{Ro} \leqq 1.2$ & 462 & 173 & \multicolumn{3}{|c|}{$460<\operatorname{Tmax} \leqq 480$} & \multicolumn{2}{|r|}{1.24} & \multicolumn{2}{|c|}{151} \\
\hline $1.2<\% \operatorname{Ro} \leqq 1.3$ & 466 & 152 & \multicolumn{3}{|c|}{$480<\operatorname{Tmax} \leqq 500$} & \multicolumn{2}{|r|}{1.40} & \multicolumn{2}{|c|}{118} \\
\hline $1.3<\% \operatorname{Ro} \leqq 1.7$ & 473 & 117 & \multicolumn{3}{|c|}{$500<\operatorname{Tmax} \leqq 559$} & & 2.05 & \multicolumn{2}{|c|}{31} \\
\hline $1.7<\% \operatorname{Ro}<3.5$ & 523 & 33 & & & & & & & \\
\hline
\end{tabular}

\subsection{Hydrocarbon Potential from Evolution of HI vs. \%Ro}

The evolution of HI with increasing \%Ro for 608 and 506 samples are shown in Figures 1a and 2a and the evolution in HI with increasing Tmax for 608 and 506 samples in Figures $1 \mathrm{~b}$ and $2 \mathrm{~b}$. In four figures, an area can be drawn around the vast majority of the samples. The HI band is widest (up to $305 \mathrm{mg} \mathrm{HC} / \mathrm{g}$ TOC broad) below Ro of approximately $0.6 \%$, as greater than which the band width of HI will be gradually reduced down to $20 \mathrm{mg} \mathrm{HC/g}$ TOC or less at Ro of about $2.1 \%$ (Figures 1a and 2a). Above this \%Ro value, HI does not show any change with increasing maturity. The HI band is widest (up to $315 \mathrm{mg} \mathrm{HC} / \mathrm{g}$ TOC) below a Tmax of about $\sim 430^{\circ} \mathrm{C}$, which, according to the relationship between $T \max$ and \%Ro, corresponds to $\sim 0.54 \%$ Ro (Figure 8 ). With increasing maturity the band width of HI will be gradually reduced down to $40 \mathrm{mg} \mathrm{HC} / \mathrm{g}$ TOC or less at a Tmax above $510^{\circ} \mathrm{C}$ (corresponds to Ro $\sim 2.05 \%$, cf. Figure 8). The upper limit of the $\mathrm{HI}$ band reaches a maximum $\mathrm{HI}$ of about $375 \mathrm{mg}$ $\mathrm{HC} / \mathrm{g}$ TOC at a $\%$ Ro of $\sim 0.6$ or a $\mathrm{Tmax}$ of $\sim 430^{\circ} \mathrm{C}$. Even though the lower limit (the organic materials with the lowest initial petroleum potential), reaches a maximum $\mathrm{HI}$ of about $\sim 110 \mathrm{mg} \mathrm{HC} / \mathrm{g}$ TOC at a $\%$ Ro of $\sim 1.0$ or a $\mathrm{Tmax}$ of $\sim 450^{\circ} \mathrm{C}$. The broad bands up to a Ro of about $0.6 \%$ and Tmax about $430^{\circ} \mathrm{C}$ reflect a distinguished variation in petroleum generation potential of the organic material with similar maturities. This can be attributed to the heterogeneous chemical component of the organic material and the different depositional environment.

Petersen (2006) suggested that the HImax line was defined between the upper limit $\left(0.6 \%\right.$ Ro or $430^{\circ} \mathrm{C}$ Tmax $)$ of the HI-band outlined by the majority of the humic coals and type III kerogen and the lower limit (1.0\%Ro or $450^{\circ} \mathrm{C}$ Tmax). Although the dissociation activation energy is higher and broader in distributed range for type II kerogen than type III kerogen, the onset of petroleum generation was similar at the early stage (Suggate et al., 1993; Hu, 2001; Sun et al., 2001). Therefore in this study, for samples of type II /III kerogen, we can obtain the same results in HImax (Sykes, 2001; Sykes and Snowdon, 2002; Pedersen et al., 2006; Petersen, 2006). The line defined by the \%Ro values $[0.6,1.0]$ and the Tmax $\left({ }^{\circ} \mathrm{C}\right)$ values $[430,450]$ in the Figure 1 represents the line of HImax, and the slope of the HImax line suggests that the organic materials with the highest petroleum potential can reach their HImax at the lowest maturity. As illustrated by Sykes and Snowdon (2002), HI values of immature organic materials or of mature organic materials that have passed beyond the line of HImax, can be extrapolated along their maturation pathways into their HImax values so as to estimate their the true petroleum potential. The effect of the gradual exhaustion of the petroleum potential is evident from the narrowing of the HI band with increasing maturity. However, the organic materials may still possess petroleum potential at a Ro up to $1.3 \%$ (HI up to $\sim 175 \mathrm{mgHC} / \mathrm{g}$ TOC) which is the end of the traditional oil window (Figures 1a, 2a). The HI shows that the generative potential for liquid petroleum of the organic materials is exhausted at a Ro of approximately $2.0-2.2 \%$ or $\mathrm{T}_{\max }$ of $510-520^{\circ} \mathrm{C}$ (Figures 1 and 2), corresponds to $2.05-2.23 \%$ Ro (Figure 8). For humic coals and kerogen type III, liquid petroleum generation is negligible at a $\%$ Ro of approximately 1.8 , and at $2.0 \%$ Ro the petroleum generative potential is exhausted (Petersen, 2002).

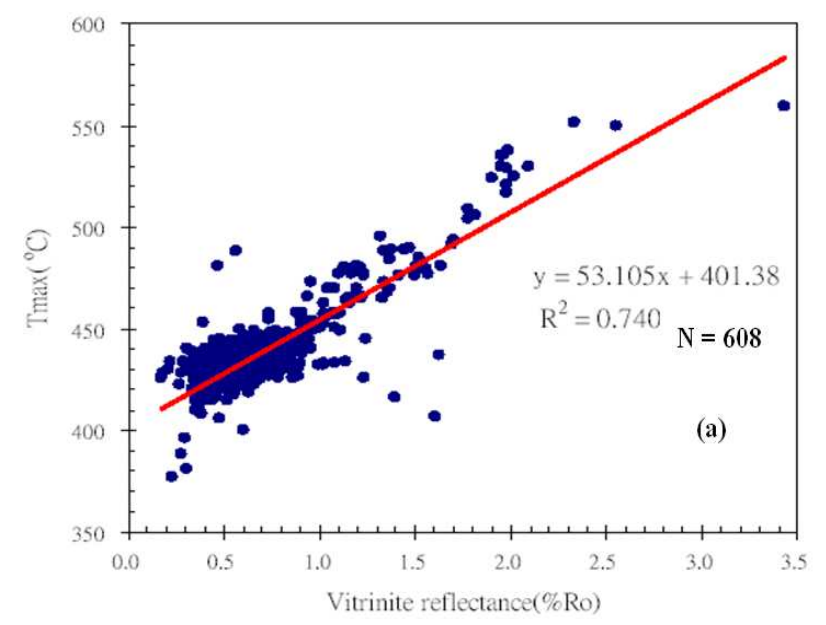




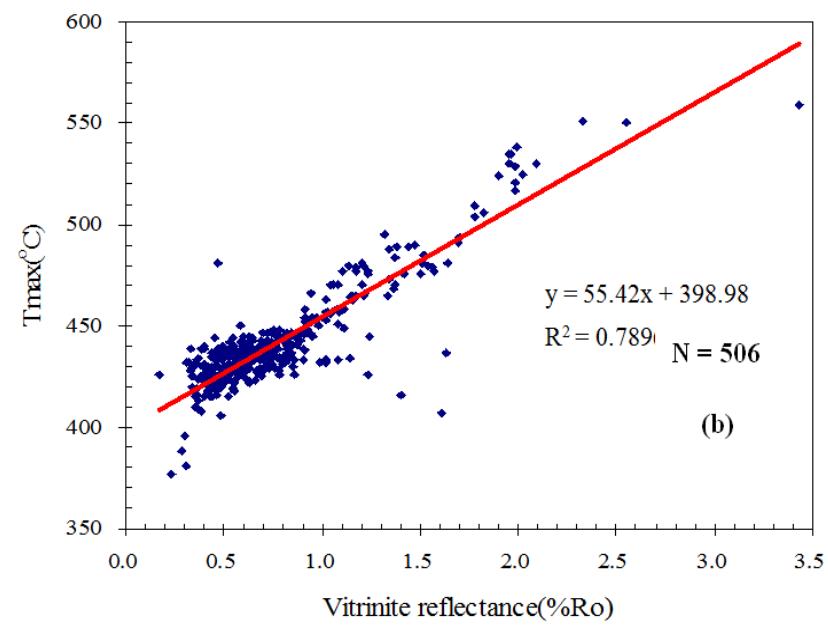

Fig. 8. Correlation between \%Ro and Tmax based on the datasets of 608 (a) and 506 (b) samples.

\subsection{QI-Band Defined by the Majority}

The Quality Index (QI, Rock-Eval derived S1+S2 yields normalized to total organic carbon, TOC) can be used to represent the total generation potential (Wang, 1998; Sykes, 2001; Sykes and Snowdon, 2002; Petersen, 2006; Rabbani and Kamali, 2005; Kotarba et al., 2007; Pepper and Corvi, 1995). From the results of descriptive analysis for the mean value of respective parameter in the interval of $\%$ Ro or $\operatorname{Tmax}\left({ }^{\circ} \mathrm{C}\right)$ span, the QI has the highest value of mean at the $\sim 0.6 \%$ Ro (within 0.5-0.7\%Ro) and $\sim 1.0 \%$ Ro (within $0.9-1.1 \% \mathrm{Ro}$ ), $\sim 430^{\circ} \mathrm{C} \mathrm{T} \max$ (within $425-435^{\circ} \mathrm{C} \mathrm{T} \max$ ) and $\sim 450{ }^{\circ} \mathrm{C}$ Tmax (within $442-460^{\circ} \mathrm{C}$ Tmax) ( Table 9). As noted previously, we can obtain the same result from the Pearson correlation analysis (Table 9b-c; Figures 5-7). The evolution in QI with increasing \%Ro for 608 and 506 samples is shown in Figures 3a and 4a. and the evolution in QI with increasing Tmax for 608 and 506 samples in Figures 3b and 4b. The data are distributed in an area (QI band) which can be drawn around the vast majority of the samples. The QI band is broadest (up to $360 \mathrm{mg} \mathrm{HC} / \mathrm{g}$ TOC broad) below a Ro of approximately $0.6 \%$, beyond which it gradually narrows to a band width of $35 \mathrm{mg} \mathrm{HC} / \mathrm{g}$ TOC or less at a Ro of about $2.2 \%$ (Figures 3a, 4a). Above this \%Ro value, the QI does not show any change with increasing maturity.

A similar evolution in QI is shown by Figures $3 \mathrm{~b}$ and $4 \mathrm{~b}$. The QI band is widest (up to $380 \mathrm{mg} \mathrm{HC/g}$ TOC) below a Tmax of about $\sim 430^{\circ} \mathrm{C}$, which, according to the relationship between Tmax and \%Ro, corresponds to $\sim 0.54 \%$ Ro (Figure 8 ). With increasing maturity the band width of QI will be gradually reduced down to $40 \mathrm{mg} \mathrm{HC} / \mathrm{g}$ TOC or less at a Tmax above $510^{\circ} \mathrm{C}(\sim 2.05 \%$ Ro, cf. Figure 5$)$. So in this study, a line of maximum QI (QImax, cf. Sykes, 2001; Sykes and Snowdon, 2002; Pedersen et al., 2006; Petersen, 2006) can be outlined between Ro $\sim 0.6 \%$ and $\sim 1.0 \%$ or Tmax $\sim 430^{\circ} \mathrm{C}$ and $\sim 450^{\circ} \mathrm{C}$. Petersen (2006) has postulated that the QImax line was defined between the apex of the upper limit $(0.7 \%$ Ro or $\left.435^{\circ} \mathrm{C} \mathrm{T}_{\max }\right)$ of the QI-band defined by the majority of the humic coals and typeIII kerogen and the apex of the lower limit (1.0\%Ro or $455^{\circ} \mathrm{C}$ Tmax). Sykes and Snowdon (2002), Petersen (2006) have interpreted about the decline in QI that indicates the commencement of initial oil expulsion. Because type $I$ kerogen possess a few bonds with low dissociated activation energy at the stage of low maturation, only few hydrocarbons of S1 and S2 can be produced and causing the decline of QI values. (Suggate et al., 1993; Hu, 2001; Sun et al., 2001; Chen, 2006). In other words, for the mixed samples of type II/III kerogen in the petroleum build-up stage, the QI value will be lower than while at the $0.6 \%$ Ro maturity, they accord with the results in this study. Therefore we can obtain the same results as HI value in the QImax .

\subsection{BI-Band Defined by the Majority}

During the evolution in BI with increasing thermal maturity (\%Ro, Tmax), the bitumen Index (BI) (Sykes, 2001; Sykes and Snowdon, 2002; Petersen, 2006; Killops et al. 1998) corresponds to the maturity (\%Ro or Tmax) at which the BI value begin to decline which represents the start of the efficient oil window, or indicates the efficient oil expulsion (Petersen, 2006). From the results of descriptive analysis for the mean value of respective parameter in the interval of $\%$ Ro or Tmax $\left({ }^{\circ} \mathrm{C}\right)$ span, the BI exhibits the highest value of mean at the $\sim 0.75 \%$ Ro (within $0.7-0.8 \%$ Ro) and $\sim 1.0 \%$ Ro (within $0.9-1.1 \%$ Ro), $\sim 440^{\circ} \mathrm{C} \quad \mathrm{Tmax}$ (within $438-450^{\circ} \mathrm{C} T \max \mathrm{x}$ ) and $\sim 452^{\circ} \mathrm{C} \mathrm{T} \max$ (within $442-460^{\circ} \mathrm{C}$ Tmax) ( Table 9). The evolution in BI with increasing \% Ro for 608 and 506 samples is shown in Figures $6 \mathrm{a}$ and $7 \mathrm{a}$. and the evolution in BI with increasing Tmax for 608 and 506 samples in Figures $6 \mathrm{~b}$ and $7 \mathrm{~b}$. The data are distributed in an area (BI band) can be outlined around the vast majority of the samples. Lewan $(1994,1997)$ suggest the early generated compounds are presumed to be bitumen or heavy crude oil which forms oil by partial decomposition at higher maturity. As pyrolysis hydrocarbon S2 is decomposed continuously, will cause the decrease of S2 and the increase of free hydrocarbon S1, further result in the increase of BI. The HI value is reduced and $\mathrm{BI}$ value will increase until the hydrocarbon reaches the equilibrium amount of efficient oil repulsion, then BI value starts to decline (Suggate et al., 1993; $\mathrm{Hu}, 2001$; Sun et al., 2001; Chan, 2006). As for samples of type $\Pi$ kerogen, there are few bonds with low dissociated activation energy at the stage of low maturation, and the free hydrocarbon (S1) lacked more than type III kerogen which can produce free hydrocarbon (S1) from the decomposed hydrocarbon (S2).

Since the samples in this study include type II /III kerogen, so their BI values will decrease gradually in lower maturity (\%Ro, Tmax) other than the samples of humic coals and type III kerogen. A cross-plot of BI vs. \%Ro shows that the majority of the organic materials form a BI band (Figures 6a, 7a). Similarly a cross-plot of BI vs. Tmax shows that the majority of the organic materials form a BI band (Figures 6b, 7b). The upper limit of the BI band shows a rapid increase from $\sim 14 \mathrm{mg} \mathrm{HC} / \mathrm{g}$ TOC at about a Tmax of $\sim 430^{\circ} \mathrm{C}$ to $\sim 40 \mathrm{mg}$ $\mathrm{HC} / \mathrm{g} \mathrm{TOC}$ at a $\mathrm{Tmax}$ of $\sim 440^{\circ} \mathrm{C}$ (Figures $6 \mathrm{~b}, 7 \mathrm{~b}$ ), which, according to the \%Ro-Tmax relationship in Fig. 8, 
corresponds to $\sim 0.73 \%$ Ro. Similarly BI vs. $\%$ Ro shows an increase in BI from $\sim 0.55 \%$ Ro to above $32 \mathrm{mg} \mathrm{HC} / \mathrm{g}$ TOC at $\sim 0.75 \%$ Ro (Figures $4 \mathrm{a}, 4 \mathrm{c}$ ). Above $\sim 0.75 \%$ Ro or $\sim 440^{\circ} \mathrm{C}$, the upper limit of the $\mathrm{BI}$ band decreases to very low yields at approximately $\sim 1.95 \%$ Ro or $\sim 525^{\circ} \mathrm{C}$. The lower limit of the BI band marks low values up to a $\%$ Ro of $\sim 0.85 \%$ Ro or Tmax of $\sim 445^{\circ} \mathrm{C}$. The maximum of the lower limit of the BI band may be set at a \%Ro of $\sim 1.05 \%$ Ro (corresponds to Tmax $\sim 455.48^{\circ} \mathrm{C}$ cf. Figure 8 ) or Tmax of $\sim 455^{\circ} \mathrm{C}$ beyond which the lower limit decreases to very low values around $\sim 1.25 \%$ Ro or $\sim 465^{\circ} \mathrm{C}$. $\operatorname{Tmax}=\sim 465^{\circ} \mathrm{C}$ corresponds to $\sim 1.2 \%$ Ro according to the \%Ro-Tmax relationship in Figure 8. The sharp increase in $\mathrm{BI}$ at a Tmax of $430-440^{\circ} \mathrm{C}$ (or corresponds to $0.54-0.73 \%$ Ro according to the \%Ro-Tmax relationship in Figure 8) marks the onset of petroleum generation (Petersen, 2002; Sykes, 2001; Sykes and Snowdon, 2002).

\subsection{Effective Oil Expulsion Window}

Petersen (2002) defined an effective oil window for source rock between vitrinite reflectance of 0.85 to $1.8 \%$. At a Ro of $1.8 \% \mathrm{~S} 1$ yields are very low and the remaining generation potential according to its HI was stabilized at low values, the threshold of petroleum generation was determined to start at a Ro of about $0.5-0.6 \%$ (Tissot and Welte, 1984) and build-up of liquid petroleum occurs from approximately $0.5-0.85 \%$ Ro. In addition, several studies have recognized the initial increase in HI up to a maximum value (HImax) with increasing maturity (Huc et al., 1986; Teichmüller and Durand, 1983; Sykes, 2001; Sykes and Snowdon, 2002). HImax corresponds to the effective HI, according to Sykes (2001) and Sykes and Snowdon (2002). The beginning of petroleum expulsion is come first by petroleum build-up to a maximum BI. Petersen (2002) proposed that the effective oil window for humic coals and TypeIIIkerogen starts at a Ro of $0.85 \%$.

The studied worldwide organic material data set shows that $\sim 0.75 \%$ Ro corresponds to the upper limit of the BI band, whereas the lower limit of the band reaches a maximum at approximately Ro $\sim 1.05 \%$ or $\operatorname{Tmax} 455^{\circ} \mathrm{C}$ (Figures6 and 7). In accordance with the results of descriptive analysis for the mean value of respective parameter in the interval of \% Ro span, BI has the highest mean value at the Ro $\sim 0.75 \%$, Tmax $440^{\circ} \mathrm{C}$ (Table 9a-b). As noted previously, we can also receive the same result from the Pearson correlation analysis (Table 8b-c, Figures 5-4). Ro from $0.17 \sim 0.6 \%$ up to $0.61 \sim 1.0 \%$, the correlation of $\mathrm{HI}$ and QI with BI turned from medium to low, as BI was increased with thermal maturity Ro up to $\sim 0.75 \%$ (Figures 5-7). On the other hand, during $\mathrm{Ro}=0.17 \sim 1.0 \%$ up to $1.0 \sim 3.43 \%$, the correlation of HI and QI with \%Ro increased, with correlative coefficient up to $\mathrm{r}=-0.72$ (Table $8 \mathrm{c}$ ). Matching with the principle of Sykes (2001) and Sykes and Snowdon (2002), the line between these two maxima (Ro 0.85-1.05\%; Tmax $440-455^{\circ} \mathrm{C}$ ) outlines the line for the efficient liquid petroleum expulsion. The maximum BI line thus corresponds to the maturity range within which the start of the oil expulsion window for worldwide data set of the studied.

\subsection{Relationships among Parameters}

From Figures 5, 9, we can examine the relationships among parameters (\%Ro, Tmax, HI, QI, BI, PI, S2, TOC, $\mathrm{S} 1+\mathrm{S} 2, \mathrm{~S} 1)$ for dataset of 608 samples. Tables 7-8, show the Pearson correlation analysis and the mean value of respective parameter in the interval of \%Ro and Tmax $\left({ }^{\circ} \mathrm{C}\right)$ span for data-sets of 608,506 , and 1140 samples respectively. The results are follows: the couple of parameters (\%Ro vs. Tmax, HI vs. QI, TOC vs. [S1+S2], S2 vs. [S1+S2], S2 vs. TOC) exhibit high correlation. The parameters have the highest value of mean with increasing thermal maturity at $\mathrm{Ro}=\sim$ $0.6 \%$ (within Ro $0.5 \sim 0.7 \%$ ) for (HI, QI, S1, S2, S1+S2), at $\mathrm{Ro}=\sim 0.75 \%$ (within Ro 0.7 0.8\%)for (BI, PI), and at Ro= $0.9 \%$ (within Ro $0.8 \sim 1.0 \%$ ) for (S1, S2, S1+S2). From dataset of 608 samples, the parameters have the highest value of mean with increasing thermal maturity at $\operatorname{Tmax}=\sim 430^{\circ} \mathrm{C}$ (within Tmax $425 \sim 435^{\circ} \mathrm{C}$ ) for (HI, QI), at $\mathrm{Tmax}=\sim 450{ }^{\circ} \mathrm{C}$ (within Tmax $442 \sim 460{ }^{\circ} \mathrm{C}$ ) for (HI, QI, BI). As for 506 samples, the parameters have the highest value of mean with increasing thermal maturity at $\operatorname{Tmax}=\sim 430{ }^{\circ} \mathrm{C}$ for (HI, QI, $\mathrm{S} 1, \mathrm{~S} 2, \mathrm{~S} 1+\mathrm{S} 2$ ), at $\mathrm{Tmax}=\sim 450^{\circ} \mathrm{C}$ for (HI, QI, BI, PI, S1, $\mathrm{S} 2, \mathrm{~S} 1+\mathrm{S} 2$ ). As in Table 9c (interval of \%Ro span), the parameter (HI) has the highest value of mean with increasing thermal maturity at Ro $=\sim 0.6 \%$ and $\sim 1.0 \%$. Furthermore, the parameter (HI) has the highest value of mean with increasing thermal maturity at the Tmax $=\sim 430{ }^{\circ} \mathrm{C}$ and $\sim$ $450^{\circ} \mathrm{C}$. Accordingly, we confirm the upper and lower limit of the $\mathrm{HI}$ and QI band, and to define to the lines of maximum $\mathrm{HI}$ and QI from Ro $\sim 0.6$ to $\sim 1.0 \%$ or from Tmax $\sim 430$ to $\sim 450^{\circ} \mathrm{C}$. Similarly, the upper and lower limit of BI band, the line of maximum BI is defined from Ro $\sim 0.75$ to $\sim 1.05 \%$ or from Tmax $\sim 440$ to $\sim 455^{\circ} \mathrm{C}$.

Table $8 \mathrm{~b}-\mathrm{c}$, show the bivariate correlation analysis of the intervals of \%Ro span for data-set of 608 samples. From $\mathrm{Ro}=0.17 \sim 0.6 \%$ to $\mathrm{Ro}=0.61 \sim 1.0 \%$ for 10 parameters, the changes of correlativity turned from medium to low for (BI vs. HI, BI vs. QI, S2 vs. QI). The correlativity rises from low to medium for PI vs. BI. From $\mathrm{Ro}=0.17 \sim 1.0 \%$ to $\mathrm{Ro}=1.0 \sim 5.6 \%$ for 10 parameters, the changes of correlativity turned from being independent to medium(negative) for (HI vs. $\%$ Ro, QI vs. $\%$ Ro), and from medium to high for Tmax vs. \%Ro, and from high to medium for (TOC vs. S2, TOC vs. $[\mathrm{S} 1+\mathrm{S} 2])$. The multiple regression analysis of $\mathrm{BI}, \mathrm{S} 2$, and \%Ro with HI (S2/TOC) and QI ([S1+S2]/TOC) show the strong positive relationship. Similarly the multiple regression analysis of HI, QI, BI, PI, S2, TOC, Tmax, and S1 with \%Ro also shows the strong positive correlation (Table 10). On the other hand, the multiple regression for 97 samples $(\mathrm{Ro}=1.0 \sim 5.6 \%)$ with $\mathrm{R}^{2}=0.94$, reach significance level of regression coefficients of independent variable, and no multicollinearity according to eigenvalue, condition index, variance proportions (Table 10). In addition, the curve regression of HI and QI with \%Ro based on 97 samples $(\mathrm{Ro}=1.0 \sim 5.6 \%)$, we can get the exponential equation of curve regression, $y=994.8 e^{-1.7 x} \quad\left(\mathrm{HI}, \mathrm{R}^{2}=0.62, \mathrm{R}=0.79\right)$, and $y=1646.2 e^{-2.0 x} \quad\left(\mathrm{QI}, \mathrm{R}^{2}=0.72, \mathrm{R}=0.87\right)$. Therefore, the oil generation potential rapidly exhausted with thermal maturity beyond $1.0 \%$ Ro and their Pearson correlation coefficient $r=$ 
-0.72 (Table 8c), in accordance with the result gained from the (Figures 1-4, 6-7).
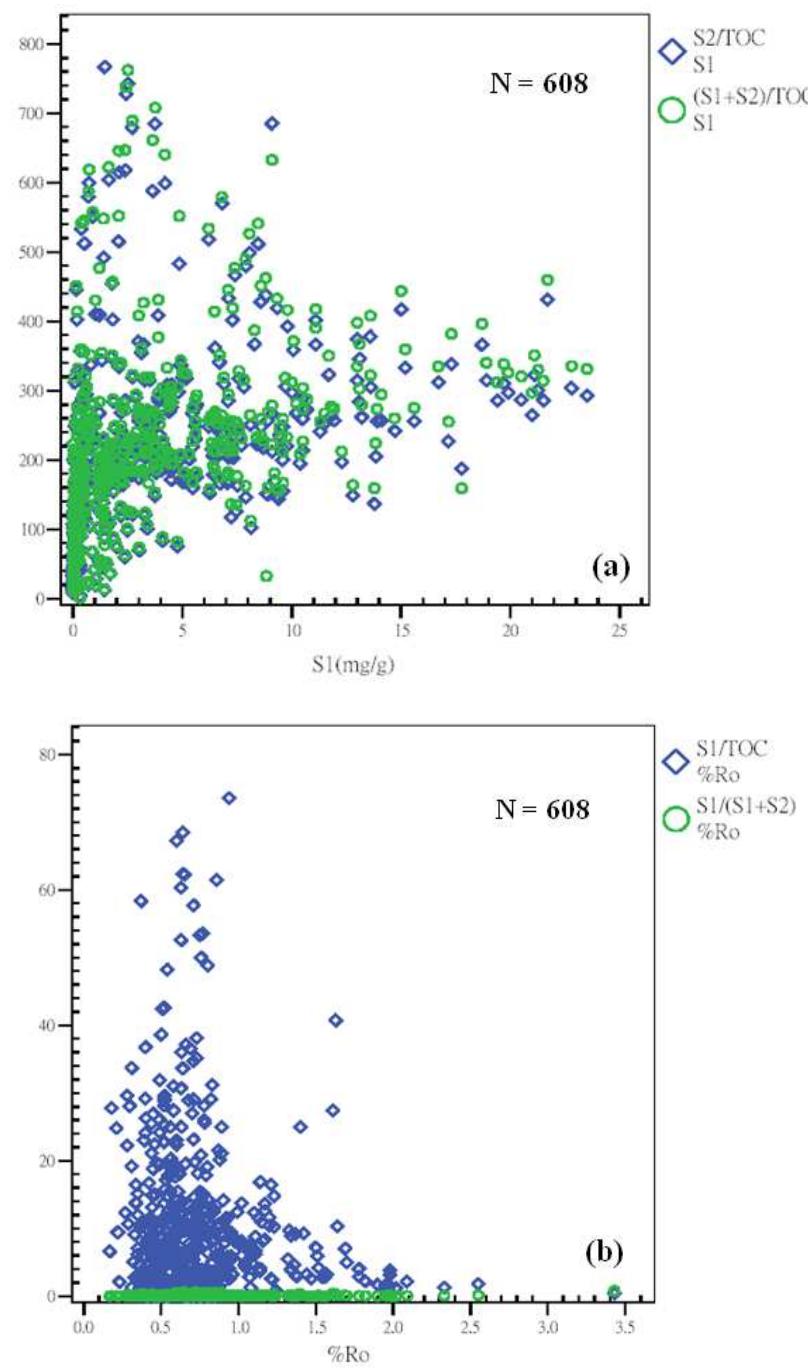
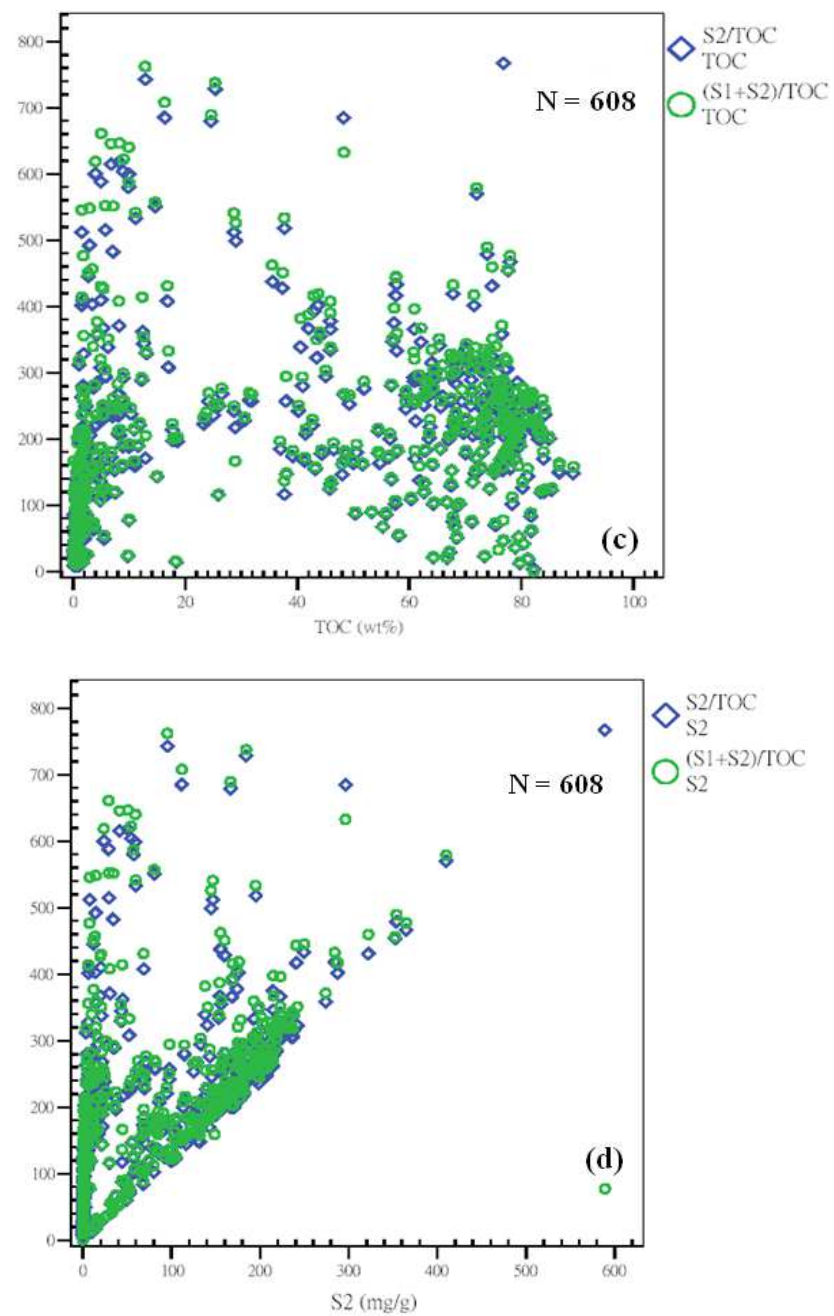

Fig. 9. Plots of (a) HI and QI (mg HC/g TOC) vs. SI, (b) BI (mg HC/g TOC) and PI vs. \%Ro, (c) HI and QI (mg HC/g TOC) vs. TOC, (d) HI and QI (mg HC/g TOC) vs. S2 (mg/g) for dataset of 608 samples.

Table 10. Multiple regression analysis for different intervals of \%Ro span in the datasets of 608 and 506 samples.

\begin{tabular}{|c|c|c|c|c|c|}
\hline \multicolumn{6}{|c|}{ multiple regression analysis } \\
\hline$\%$ Ro & $0.17 \sim 0.60$ & 0.61 1.00 & $0.17 \sim 1.00$ & $1.00 \sim 5.60$ & $0.17 \sim 5.60$ \\
\hline Sample number & 245 & 266 & 511 & 97 & 608 \\
\hline (A) adjusted $\mathrm{R}^{2}$ & 0.01 & 0.02 & 0.07 & 0.75 & 0.36 \\
\hline (B) adjusted $\mathrm{R}^{2}$ & 0.12 & 0.03 & 0.02 & 0.52 & 0.22 \\
\hline (C) adjusted $\mathrm{R}^{2}$ & 0.19 & 0.25 & 0.46 & 0.94 & 0.81 \\
\hline (D) adjusted $\mathrm{R}^{2}$ & 0.28 & 0.26 & 0.39 & 0.87 & 0.76 \\
\hline (E) adjusted $\mathrm{R}^{2}$ & 0.48 & 0.44 & 0.46 & 0.75 & 0.51 \\
\hline (F) adjusted $\mathrm{R}^{2}$ & 0.51 & 0.39 & 0.47 & 0.76 & 0.50 \\
\hline \multirow{6}{*}{$\begin{array}{l}\text { (C) Rep } \\
\text { (D) Rep } \\
\text { (E) Rep } \\
\text { (F) Rep }\end{array}$} & regression a & HI, QI, BI, P & nd S2 with & & \\
\hline & regression a & HI, QI, BI, P & nd S2 with & & \\
\hline & regression a & HI, QI, BI, P & 2 and Tmax & & \\
\hline & regression a & II, QI, BI, P & 2 and $\%$ Ro & & \\
\hline & regression a & $3 \mathrm{I}, \mathrm{S} 2$, and $\mathrm{O}$ & & & \\
\hline & regression al & $3 \mathrm{I}, \mathrm{S} 2$, and $\%$ & & & \\
\hline
\end{tabular}

(a) For the 97 samples $(\% \mathrm{Ro}=1.0 \sim 5.6)$, the $\mathrm{t}$-values for regression coefficients of independent variables reach significance level $(\mathrm{p}<0.05)$, and no multicollinearity

(b) according to tolerance[ $>0], \operatorname{VIF}[<10]$, eigenvalue[ $>0]$, condition index $[<30]$, variance proportion $[<1]$ 


\subsection{Comparison Analysis of Petroleum Potential}

Synthesizing the above analysis, we can divide petroleum potential into four different regions, based on cross-plot of $\mathrm{HI}$ vs. \%Ro (Figures 10a-b). The highest petroleum potential occurred in the second part (II), including 226 and 211 sample data $(\mathrm{Ro}=0.6-1.0 \%, \mathrm{HI}>100)$ from the datasets of 608 and 506 samples (Figures 10a-b) respectively. The first part ( I ) represents the region of petroleum generation, and the forth part (IV) exhibits the region of lowest petroleum potential, and the oil generation potential was rapidly exhausted in the third part (III). The sample data of parameters for CJ1-38 samples, TW1-48 samples, ML1-59 samples, and AU1-13 samples were present in Table 11. The CJ1-38 samples from oilfield in eastern Junggar Basin, China (Chen, 2003), whereas the others samples were detected in this study. For CJ1-38, TW1-48, ML1-59, and AU1-13 samples, the evolution in the remaining petroleum potential (HI) with increasing thermal maturity is shown in Figure 10c. The majority of CJ1-38 samples are in the second part (II) (Figure 10c; the region of highest petroleum potential, cf. Figures 10a-b). The Pearson correlation analysis for datasets of 226 and CJ1-38 samples, the couple of parameters (BI vs. HI, BI vs. QI) have medium correlation (Table 12); as for the couple of the parameters ([S1+S2, S1] vs. [HI, QI, BI]) have no correlation for datasets of 226 and CJ1-38 samples in the second part ( II ). On the other hand, the couple of parameters (S2 vs. TOC, [S1+S2] vs. TOC, S1 vs. TOC) exhibit high correlation for datasets of 226 and CJ1-38 samples (Table 12, Figures 9), in accordance with the result that possess highest petroleum potential of CJ1-38 samples. The AU1-13 samples are in the third and forth parts (III/IV), with oil generation potential rapidly exhausted. The ML1-59 samples are in the first and second parts ( I / II ), the TW1-48 samples are in the first part ( I ), both represent the region of petroleum generation (Figure 10c).

They exhibit high correlation for the couple parameters (S2 vs. HI, [S1+S2] vs. HI, S1 vs. HI, S2 vs. QI, [S1+S2] vs. QI, S1 vs. QI, HI vs. BI, QI vs. BI) for AU1-13, ML1-59, and TW1-48 samples. Therefore, four datasets except CJ1-38 samples are similarly in the correlation for couple of parameters of respective datasets (Table 12). The non-parameteric tests (2-Independent Samples) for the datasets of TW1-48 and CJ1-38 samples, they exhibit significantly different $(p>\alpha)$ for the distribution of data from respective parameters except $\mathrm{S} 1$ (Table $7 \mathrm{~d}$ ), also in accordance with CJ1-38 samples which possess the highest petroleum potential in the second part (II) (Figure 10c). According to Table 13, the CJ1-38 samples also have the highest mean value of $\mathrm{HI}$ and QI for the five data-sets (226, CJ1-38, TW1-48, ML1-59, AU1-13) although with the lowest mean value of TOC and S2. Because of the good correlation of $\mathrm{S} 2, \mathrm{~S} 1$, and $\mathrm{S} 1+\mathrm{S} 2$ with $\mathrm{TOC}$, they were believed to have few inert organic carbon (Dahl, 2004), that explained their highest petroleum potential (Table 13, Figures 9c-d).
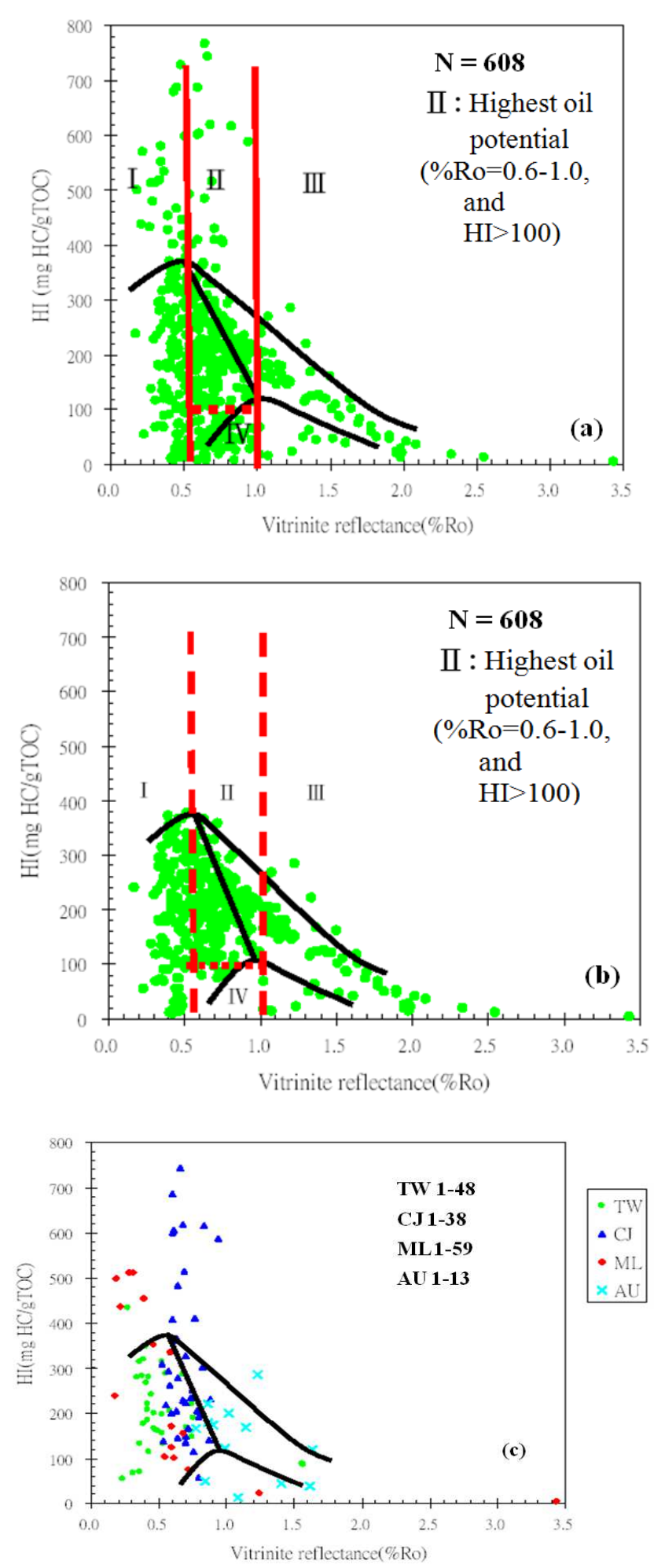

Fig. 10. The diagrams show the evolution in HI with increasing thermal maturity for datasets of 608 samples (a) and 506 samples (b). The plot (c) shows the evolution in the remaining petroleum potential (HI) with increasing thermal maturity for CJ1-38 samples, TW1-48 samples, ML1-59 samples, and AU1-13 samples. 
Table 11. This form shows the value of parameters for datasets of T1-48 samples, M1-59 samples, and AU1-13 samples. They were detected in this study.

\begin{tabular}{|c|c|c|c|c|c|c|c|c|c|c|}
\hline No. & Ro\% & Tmax & S1 & S2 & TOC & HI & $\mathbf{S} 1+\mathbf{S} 2$ & BI & QI & PI \\
\hline ML001 & 0.68 & 438 & 0.41 & 12.02 & 5.26 & 229.00 & 12.43 & 7.79 & 236.31 & 0.03 \\
\hline ML002 & 0.73 & 433 & 9.43 & 183.88 & 78.40 & 235.00 & 193.31 & 12.03 & 246.57 & 0.05 \\
\hline ML003 & 0.59 & 429 & 3.75 & 133.26 & 67.01 & 199.00 & 137.01 & 5.60 & 204.46 & 0.03 \\
\hline ML004 & 0.82 & 440 & 21.26 & 220.09 & 73.13 & 301.00 & 241.35 & 29.07 & 330.03 & 0.09 \\
\hline ML005 & 0.52 & 438 & 0.57 & 15.05 & 4.88 & 308.00 & 15.62 & 11.68 & 320.08 & 0.04 \\
\hline ML006 & 0.53 & 436 & 0.26 & 3.27 & 2.37 & 138.00 & 3.53 & 10.97 & 148.95 & 0.07 \\
\hline ML007 & 0.57 & 437 & 0.61 & 16.92 & 5.76 & 294.00 & 17.53 & 10.59 & 304.34 & 0.03 \\
\hline ML008 & 0.63 & 435 & 0.79 & 17.15 & 8.38 & 205.00 & 17.94 & 9.43 & 214.08 & 0.04 \\
\hline ML009 & 0.88 & 443 & 1.06 & 12.17 & 5.26 & 231.00 & 13.23 & 20.15 & 251.52 & 0.08 \\
\hline ML010 & 0.70 & 447 & 0.50 & 6.06 & 1.85 & 328.00 & 6.59 & 27.03 & 356.22 & 0.08 \\
\hline ML011 & 0.69 & 446 & 2.09 & 29.43 & 5.71 & 515.00 & 31.52 & 36.60 & 552.01 & 0.07 \\
\hline ML012 & 0.70 & 438 & 0.34 & 5.44 & 3.67 & 148.00 & 5.78 & 9.26 & 157.49 & 0.06 \\
\hline ML013 & 0.64 & 443 & 2.19 & 9.73 & 3.51 & 277.00 & 11.92 & 62.39 & 339.60 & 0.18 \\
\hline ML014 & 0.63 & 445 & 3.22 & 19.58 & 5.34 & 367.00 & 22.80 & 60.30 & 426.97 & 0.14 \\
\hline ML015 & 0.63 & 445 & 6.47 & 44.53 & 12.31 & 362.00 & 51.00 & 52.56 & 414.30 & 0.13 \\
\hline ML016 & 0.72 & 447 & 0.11 & 2.01 & 1.22 & 165.00 & 2.12 & 9.02 & 173.77 & 0.05 \\
\hline ML017 & 0.94 & 441 & 3.64 & 29.09 & 4.95 & 588.00 & 32.73 & 73.54 & 661.21 & 0.11 \\
\hline ML018 & 0.78 & 435 & 0.77 & 6.10 & 2.96 & 206.00 & 6.87 & 26.01 & 232.09 & 0.11 \\
\hline ML019 & 0.66 & 449 & 2.51 & 95.43 & 12.85 & 743.00 & 97.94 & 19.53 & 762.18 & 0.03 \\
\hline ML020 & 0.79 & 444 & 0.38 & 4.07 & 2.12 & 192.00 & 4.45 & 17.92 & 209.91 & 0.09 \\
\hline ML021 & 0.83 & 448 & 2.10 & 41.43 & 6.74 & 615.00 & 43.53 & 31.16 & 645.85 & 0.05 \\
\hline ML022 & 0.64 & 444 & 4.86 & 34.25 & 7.09 & 483.00 & 39.11 & 68.55 & 551.62 & 0.12 \\
\hline ML023 & 0.70 & 440 & 0.05 & 1.13 & 0.83 & 136.00 & 1.18 & 6.02 & 142.17 & 0.04 \\
\hline ML024 & 0.75 & 448 & 0.29 & 2.17 & 1.88 & 115.00 & 2.46 & 15.43 & 130.85 & 0.12 \\
\hline ML025 & 0.60 & 441 & 1.21 & 7.37 & 1.80 & 409.00 & 8.58 & 67.22 & 476.67 & 0.14 \\
\hline ML026 & 0.60 & 447 & 3.75 & 111.71 & 16.31 & 685.00 & 115.46 & 22.99 & 707.91 & 0.03 \\
\hline ML027 & 0.61 & 447 & 1.63 & 54.31 & 8.99 & 604.00 & 55.94 & 18.13 & 622.25 & 0.03 \\
\hline ML028 & 0.60 & 446 & 0.74 & 23.64 & 3.94 & 600.00 & 24.38 & 18.78 & 618.78 & 0.03 \\
\hline ML029 & 0.76 & 441 & 1.03 & 20.23 & 4.94 & 410.00 & 21.26 & 20.85 & 430.36 & 0.05 \\
\hline ML030 & 0.68 & 446 & 2.38 & 50.84 & 8.23 & 618.00 & 53.22 & 28.92 & 646.66 & 0.04 \\
\hline ML031 & 0.87 & 441 & 0.34 & 2.23 & 1.58 & 141.00 & 2.57 & 21.52 & 162.66 & 0.13 \\
\hline ML032 & 0.79 & 444 & 0.11 & 0.64 & 1.14 & 56.00 & 0.75 & 9.65 & 65.79 & 0.15 \\
\hline ML033 & 0.64 & 439 & 0.39 & 5.22 & 3.58 & 146.00 & 5.61 & 10.89 & 156.70 & 0.07 \\
\hline ML034 & 0.55 & 434 & 0.20 & 3.47 & 1.59 & 218.00 & 3.76 & 12.58 & 236.48 & 0.05 \\
\hline ML035 & 0.58 & 437 & 0.20 & 4.20 & 1.60 & 263.00 & 4.40 & 12.50 & 275.00 & 0.05 \\
\hline ML036 & 0.61 & 436 & 1.30 & 43.32 & 12.59 & 344.00 & 44.62 & 10.33 & 354.41 & 0.03 \\
\hline ML037 & 0.70 & 440 & 2.19 & 51.91 & 23.28 & 223.00 & 54.10 & 9.41 & 232.39 & 0.04 \\
\hline ML038 & 0.74 & 431 & 6.45 & 124.79 & 49.29 & 253.00 & 131.24 & 13.09 & 266.26 & 0.05 \\
\hline M1 & 5.60 & 374 & 0.51 & 0.51 & 88.64 & 0.58 & 1.02 & 0.01 & 0.01 & 0.50 \\
\hline
\end{tabular}


Table 11. (Continued)

\begin{tabular}{|c|c|c|c|c|c|c|c|c|c|c|}
\hline No. & Ro\% & Tmax & S1 & S2 & TOC & HI & $\mathbf{S 1 + S 2}$ & BI & QI & PI \\
\hline M2 & 0.69 & 424 & 0.97 & 160.54 & 73.80 & 217.54 & 161.51 & 0.01 & 2.19 & 0.01 \\
\hline M3 & 0.99 & 430 & 0.43 & 75.16 & 56.28 & 133.55 & 75.59 & 0.01 & 1.34 & 0.01 \\
\hline M4 & 0.59 & 421 & 1.74 & 176.40 & 66.50 & 265.25 & 178.14 & 0.03 & 2.68 & 0.01 \\
\hline M5 & 0.66 & 429 & 0.71 & 102.04 & 68.77 & 148.37 & 102.75 & 0.01 & 1.49 & 0.01 \\
\hline ML1 & 0.31 & 440 & 0.52 & 7.90 & 1.54 & 511.99 & 8.42 & 33.70 & 545.69 & 0.06 \\
\hline ML10 & 0.68 & 429 & 1.44 & 113.15 & 72.83 & 155.36 & 114.59 & 1.98 & 157.34 & 0.01 \\
\hline ML11 & 0.59 & 432 & 1.27 & 92.18 & 74.36 & 123.96 & 93.45 & 1.71 & 125.67 & 0.01 \\
\hline ML12 & 1.24 & 445 & 0.60 & 16.89 & 73.45 & 23.00 & 17.49 & 0.82 & 23.81 & 0.03 \\
\hline ML13 & 0.72 & 432 & 1.98 & 52.79 & 71.14 & 74.21 & 54.77 & 2.78 & 76.99 & 0.04 \\
\hline ML14 & 0.17 & 426 & 0.48 & 17.37 & 7.27 & 239.03 & 17.85 & 6.61 & 245.63 & 0.03 \\
\hline ML15 & 0.61 & 437 & 1.15 & 70.09 & 68.91 & 101.72 & 71.24 & 1.67 & 103.39 & 0.02 \\
\hline ML16 & 3.43 & 559 & 0.32 & 0.08 & 82.22 & 4.00 & 0.40 & 0.40 & 0.49 & 0.80 \\
\hline ML2 & 0.28 & 428 & 8.47 & 146.53 & 28.65 & 511.48 & 155.00 & 29.57 & 541.05 & 0.05 \\
\hline ML3 & 0.21 & 430 & 8.81 & 155.32 & 35.50 & 437.51 & 164.13 & 24.82 & 462.33 & 0.05 \\
\hline ML4 & 0.18 & 428 & 8.07 & 144.61 & 29.01 & 498.54 & 152.68 & 27.82 & 526.36 & 0.05 \\
\hline ML5 & 0.54 & 429 & 0.74 & 69.44 & 66.64 & 104.21 & 70.18 & 1.11 & 105.32 & 0.01 \\
\hline ML6 & 0.59 & 429 & 1.17 & 123.13 & 71.94 & 171.15 & 124.30 & 1.63 & 172.78 & 0.01 \\
\hline ML7 & 0.58 & 450 & 2.08 & 153.41 & 45.91 & 334.13 & 155.49 & 4.53 & 338.66 & 0.01 \\
\hline ML8 & 0.39 & 453 & 1.78 & 352.47 & 77.64 & 453.96 & 354.25 & 2.29 & 456.25 & 0.01 \\
\hline ML9 & 0.45 & 444 & 3.11 & 156.04 & 44.03 & 354.38 & 159.15 & 7.06 & 361.44 & 0.02 \\
\hline $\mathrm{T} 1$ & 0.44 & 429 & 1.39 & 160.64 & 75.30 & 213.34 & 162.03 & 0.02 & 2.15 & 0.01 \\
\hline $\mathrm{T} 2$ & 0.55 & 434 & 3.03 & 135.35 & 63.43 & 213.38 & 138.38 & 0.05 & 2.18 & 0.02 \\
\hline $\mathrm{T} 3$ & 0.53 & 425 & 5.82 & 211.86 & 70.46 & 300.68 & 217.68 & 0.08 & 3.09 & 0.03 \\
\hline $\mathrm{T} 4$ & 0.27 & 414 & 3.97 & 143.46 & 65.38 & 219.41 & 147.43 & 0.06 & 2.25 & 0.03 \\
\hline $\mathrm{T} 5$ & 0.29 & 419 & 3.26 & 194.45 & 72.43 & 268.45 & 197.71 & 0.05 & 2.73 & 0.02 \\
\hline T6 & 0.39 & 428 & 2.29 & 134.06 & 68.55 & 195.56 & 136.35 & 0.03 & 1.99 & 0.02 \\
\hline $\mathrm{T} 7$ & 0.77 & 437 & 8.31 & 216.84 & 78.62 & 275.80 & 225.15 & 0.11 & 2.86 & 0.04 \\
\hline $\mathrm{T} 8$ & 0.25 & 418 & 4.18 & 170.40 & 49.19 & 346.44 & 174.58 & 0.08 & 3.55 & 0.02 \\
\hline T9 & 0.34 & 413 & 3.14 & 157.22 & 50.09 & 313.89 & 160.36 & 0.06 & 3.20 & 0.02 \\
\hline $\mathrm{T} 10$ & 0.58 & 419 & 7.93 & 229.48 & 64.39 & 356.39 & 237.41 & 0.12 & 3.69 & 0.03 \\
\hline T11 & 0.26 & 421 & 4.63 & 217.11 & 61.73 & 351.73 & 221.74 & 0.08 & 3.59 & 0.02 \\
\hline T12 & 0.39 & 420 & 4.13 & 150.00 & 47.40 & 316.47 & 154.13 & 0.09 & 3.25 & 0.03 \\
\hline TW1 & 0.74 & 434 & 1.28 & 111.28 & 75.16 & 148.06 & 112.56 & 1.70 & 149.77 & 0.01 \\
\hline TW10 & 0.75 & 437 & 1.64 & 150.92 & 79.80 & 189.12 & 152.56 & 2.06 & 191.18 & 0.01 \\
\hline TW11 & 0.73 & 441 & 1.35 & 103.22 & 64.12 & 160.97 & 104.57 & 2.11 & 163.08 & 0.01 \\
\hline TW12 & 0.23 & 377 & 1.22 & 31.42 & 58.10 & 54.08 & 32.64 & 2.10 & 56.18 & 0.04 \\
\hline TW13 & 0.36 & 431 & 3.30 & 224.00 & 71.17 & 314.74 & 227.30 & 4.64 & 319.38 & 0.01 \\
\hline TW14 & 1.57 & 477 & 1.84 & 47.76 & 55.88 & 85.47 & 49.60 & 3.29 & 88.76 & 0.04 \\
\hline TW15 & 1.56 & 479 & 1.44 & 43.87 & 50.37 & 87.09 & 45.31 & 2.86 & 89.95 & 0.03 \\
\hline TW16 & 0.27 & 423 & 7.09 & 249.63 & 57.63 & 433.13 & 256.72 & 12.30 & 445.43 & 0.03 \\
\hline TW17 & 0.36 & 416 & 1.01 & 61.51 & 46.02 & 133.67 & 62.52 & 2.19 & 135.86 & 0.02 \\
\hline
\end{tabular}


22 Hsien-Tsung Lee: A Comparison between Statistical Analysis and Grey Model Analysis on Assessed Parameters of Petroleum Potential from Organic Materials

Table 11. (Continued)

\begin{tabular}{|c|c|c|c|c|c|c|c|c|c|c|}
\hline No. & Ro\% & Tmax & S1 & S2 & TOC & HI & $\mathbf{S 1 + S 2}$ & BI & QI & PI \\
\hline TW18 & 0.41 & 418 & 1.78 & 198.41 & 57.04 & 347.86 & 200.19 & 3.12 & 350.98 & 0.01 \\
\hline TW19 & 0.52 & 424 & 3.50 & 229.69 & 72.91 & 315.01 & 233.19 & 4.80 & 319.82 & 0.02 \\
\hline TW2 & 0.53 & 431 & 0.68 & 83.51 & 62.62 & 133.37 & 84.19 & 1.09 & 134.46 & 0.01 \\
\hline TW20 & 0.41 & 425 & 2.89 & 86.05 & 41.47 & 207.48 & 88.94 & 6.97 & 214.45 & 0.03 \\
\hline TW21 & 0.42 & 424 & 3.64 & 94.27 & 42.67 & 220.94 & 97.91 & 8.53 & 229.47 & 0.04 \\
\hline TW22 & 0.45 & 423 & 3.33 & 97.48 & 40.25 & 242.20 & 100.81 & 8.27 & 250.47 & 0.03 \\
\hline TW23 & 0.47 & 424 & 2.20 & 69.09 & 41.35 & 167.09 & 71.29 & 5.32 & 172.41 & 0.03 \\
\hline TW24 & 0.47 & 422 & 2.29 & 81.62 & 49.98 & 163.30 & 83.91 & 4.85 & 167.88 & 0.03 \\
\hline TW25 & 0.46 & 418 & 4.48 & 113.06 & 56.53 & 200.00 & 117.54 & 7.92 & 207.92 & 0.04 \\
\hline TW26 & 0.50 & 426 & 1.42 & 83.16 & 51.66 & 160.99 & 84.58 & 2.75 & 163.73 & 0.02 \\
\hline TW27 & 0.43 & 423 & 0.32 & 30.01 & 25.97 & 115.57 & 30.33 & 1.23 & 116.80 & 0.01 \\
\hline TW28 & 0.34 & 420 & 5.66 & 114.45 & 40.91 & 279.80 & 120.11 & 13.84 & 293.63 & 0.05 \\
\hline TW29 & 0.42 & 418 & 4.50 & 85.49 & 46.43 & 184.12 & 89.99 & 9.69 & 193.81 & 0.05 \\
\hline TW3 & 0.58 & 429 & 1.35 & 138.93 & 67.69 & 205.25 & 140.28 & 1.99 & 207.25 & 0.01 \\
\hline TW30 & 0.71 & 438 & 1.63 & 133.17 & 78.88 & 168.84 & 134.80 & 2.07 & 170.90 & 0.01 \\
\hline TW31 & 0.41 & 417 & 0.76 & 129.04 & 48.32 & 267.00 & 129.80 & 1.57 & 268.63 & 0.01 \\
\hline TW32 & 0.38 & 425 & 1.83 & 179.08 & 62.97 & 284.00 & 180.91 & 2.91 & 287.30 & 0.01 \\
\hline TW33 & 0.31 & 432 & 0.85 & 45.53 & 68.11 & 67.00 & 46.38 & 1.25 & 68.10 & 0.02 \\
\hline TW34 & 0.43 & 415 & 0.90 & 159.81 & 56.79 & 281.00 & 160.71 & 1.58 & 282.99 & 0.01 \\
\hline TW35 & 0.55 & 418 & 0.44 & 35.23 & 12.20 & 289.00 & 35.67 & 3.61 & 292.38 & 0.01 \\
\hline TW36 & 0.39 & 426 & 2.73 & 216.84 & 67.94 & 319.00 & 219.57 & 4.02 & 323.18 & 0.01 \\
\hline TW4 & 0.39 & 430 & 2.69 & 78.42 & 44.28 & 177.12 & 81.11 & 6.08 & 183.20 & 0.03 \\
\hline TW5 & 0.52 & 425 & 1.21 & 36.49 & 18.58 & 196.38 & 37.70 & 6.51 & 202.90 & 0.03 \\
\hline TW6 & 0.52 & 427 & 1.22 & 67.07 & 43.22 & 155.18 & 68.29 & 2.82 & 158.01 & 0.02 \\
\hline TW7 & 0.36 & 433 & 0.07 & 1.57 & 2.23 & 70.53 & 1.64 & 3.14 & 73.67 & 0.04 \\
\hline TW8 & 0.74 & 437 & 2.42 & 175.15 & 79.20 & 221.16 & 177.57 & 3.06 & 224.22 & 0.01 \\
\hline TW9 & 0.68 & 435 & 2.39 & 212.47 & 79.26 & 286.07 & 214.86 & 3.02 & 271.09 & 0.01 \\
\hline AU1 & 1.63 & 437 & 0.30 & 0.87 & 0.74 & 118.21 & 1.17 & 40.76 & 158.97 & 0.26 \\
\hline AU10 & 0.77 & 434 & 0.26 & 2.92 & 1.75 & 167.14 & 3.18 & 14.88 & 182.03 & 0.08 \\
\hline AU11 & 0.86 & 426 & 2.32 & 8.32 & 3.78 & 220.40 & 10.64 & 61.46 & 281.85 & 0.22 \\
\hline AU14 & 1.08 & 433 & 0.23 & 2.61 & 18.30 & 14.26 & 2.84 & 1.26 & 15.52 & 0.08 \\
\hline AU15 & 0.84 & 432 & 0.17 & 1.03 & 2.04 & 50.42 & 1.20 & 8.32 & 58.74 & 0.14 \\
\hline AU2 & 1.61 & 407 & 0.11 & 0.16 & 0.40 & 39.90 & 0.27 & 27.43 & 67.33 & 0.41 \\
\hline AU3 & 1.40 & 416 & 0.10 & 0.18 & 0.40 & 45.00 & 0.28 & 25.00 & 70.00 & 0.36 \\
\hline AU4 & 1.14 & 434 & 0.29 & 2.88 & 1.72 & 167.54 & 3.17 & 16.87 & 184.41 & 0.09 \\
\hline AU5 & 1.23 & 426 & 3.90 & 12.06 & 4.23 & 284.84 & 15.96 & 92.11 & 376.95 & 0.24 \\
\hline AU6 & 0.90 & 433 & 0.26 & 3.18 & 1.84 & 173.20 & 3.44 & 14.16 & 187.36 & 0.08 \\
\hline AU7 & 0.99 & 432 & 0.25 & 2.46 & 2.01 & 122.21 & 2.71 & 12.42 & 134.62 & 0.09 \\
\hline AU8 & 0.86 & 433 & 0.28 & 3.74 & 2.10 & 178.35 & 4.02 & 13.35 & 191.70 & 0.07 \\
\hline AU9 & 1.02 & 433 & 0.26 & 3.78 & 1.90 & 199.26 & 4.04 & 13.71 & 212.97 & 0.06 \\
\hline
\end{tabular}


Table 12. Distribution of Pearson's correlation coefficient of datasets of 226, CJ38, TW48, ML59, and AU13 samples

\begin{tabular}{|c|c|c|c|c|c|}
\hline \multirow{2}{*}{ Datasets } & & \multicolumn{4}{|c|}{ Pearson's correlation coefficient (r) r (couple of parameters) } \\
\hline & & $\mathbf{G}$ & $\mathbf{M}$ & $\mathbf{L}$ & $\mathbf{E L}$ \\
\hline a & $\begin{array}{l}0.6 \leqq \% \text { Ro } \leqq 1.0 \\
226 \text { samples }\end{array}$ & $\begin{array}{l}0.88(\mathrm{~S} \text { vs } \mathrm{C}) \\
0.89(\mathrm{C} \text { vs } \mathrm{A}) \\
0.82(\mathrm{~B} \text { vs } \mathrm{P})\end{array}$ & $\begin{array}{l}0.58(\mathrm{Q} \text { vs } \mathrm{B}) \\
0.54(\mathrm{C} \text { vs } \mathrm{D})\end{array}$ & $0.44(\mathrm{H}$ vs B) & $\begin{array}{l}(\mathrm{H} \text { vs } \mathrm{S})(\mathrm{Q} \text { vs } \mathrm{S})(\mathrm{B} \text { vs } \mathrm{S}) \\
(\mathrm{H} \text { vs } \mathrm{A})(\mathrm{Q} \text { vs } \mathrm{A})(\mathrm{B} \text { vs } \mathrm{A}) \\
(\mathrm{H} \text { vs } \mathrm{D})(\mathrm{Q} \text { vs } \mathrm{D})(\mathrm{B} \text { vs } \mathrm{D})\end{array}$ \\
\hline b & $\begin{array}{l}0.52 \leqq \% \mathrm{Ro} \leqq 0.94 \\
\text { CJ } 38 \\
38 \text { samples }\end{array}$ & $\begin{array}{l}0.94(\mathrm{~S} \text { vs } \mathrm{C}) \\
0.93(\mathrm{C} \text { vs } \mathrm{A})\end{array}$ & $\begin{array}{l}0.52(\mathrm{Q} \text { vs } \mathrm{B}) \\
0.78(\mathrm{C} \text { vs } \mathrm{D}) \\
0.67(\mathrm{~B} \text { vs } \mathrm{P})\end{array}$ & 0.43 (H vs B) & $\begin{array}{l}(\mathrm{H} \text { vs } \mathrm{S})(\mathrm{Q} \text { vs } \mathrm{S})(\mathrm{B} \text { vs } \mathrm{S}) \\
(\mathrm{H} \text { vs } \mathrm{A})(\mathrm{Q} \text { vs } \mathrm{A})(\mathrm{B} \text { vs } \mathrm{A}) \\
(\mathrm{H} \text { vs } \mathrm{D})(\mathrm{Q} \text { vs } \mathrm{D})(\mathrm{B} \text { vs } \mathrm{D})\end{array}$ \\
\hline c & $\begin{array}{l}0.23 \leqq \% \text { Ro } \leqq 1.57 \\
\text { TW } 48 \\
48 \text { samples }\end{array}$ & $\begin{array}{l}0.83(\mathrm{H} \text { vs } \mathrm{S}) \\
0.81(\mathrm{Q} \text { vs } \mathrm{S}) \\
0.83(\mathrm{H} \text { vs } \mathrm{A}) \\
0.82(\mathrm{Q} \text { vs } \mathrm{A}) \\
0.88(\mathrm{~B} \text { vs } \mathrm{D})\end{array}$ & $\begin{array}{l}0.66(\mathrm{~S} \text { vs } \mathrm{C}) \\
0.65(\mathrm{C} \text { vs } \mathrm{A}) \\
0.55(\mathrm{H} \text { vs } \mathrm{D}) \\
0.58(\mathrm{Q} \text { vs } \mathrm{D}) \\
0.691(\mathrm{~B} \text { vs } \mathrm{P})\end{array}$ & $\begin{array}{l}0.42(\mathrm{H} \text { vs } \mathrm{B}) \\
0.45(\mathrm{Q} \text { vs } \mathrm{B})\end{array}$ & $0.16(C$ vs $D)$ \\
\hline d & $\begin{array}{l}0.17 \leqq \% \text { Ro } \leqq 5.60 \\
\text { ML } 59 \\
59 \text { samples }\end{array}$ & $\begin{array}{l}0.81(\mathrm{H} \text { vs } \mathrm{B}) \\
0.83(\mathrm{Q} \text { vs } \mathrm{B})\end{array}$ & $\begin{array}{l}0.691(\mathrm{~B} \text { vs } \mathrm{P}) \\
0.54(\mathrm{H} \text { vs } \mathrm{S}) \\
0.52(\mathrm{Q} \text { vs } \mathrm{S}) \\
0.65(\mathrm{H} \text { vs } \mathrm{D}) \\
0.66(\mathrm{Q} \text { vs } \mathrm{D}) \\
-0.70(\mathrm{H} \text { vs } \mathrm{C}) \\
-0.71(\mathrm{Q} \text { vs } \mathrm{C})\end{array}$ & $-0.38(C$ vs $\mathrm{D})$ & $\begin{array}{l}0.14(\mathrm{~S} \text { vs } \mathrm{C}) \\
0.13(\mathrm{C} \text { vs } \mathrm{A}) \\
-0.12(\mathrm{~B} \text { vs } \mathrm{P})\end{array}$ \\
\hline $\mathbf{e}$ & $\begin{array}{l}0.77 \leqq \% \mathrm{Ro} \leqq 1.63 \\
\text { AU13 } \\
13 \text { samples }\end{array}$ & $\begin{array}{l}0.82(\mathrm{H} \text { vs } \mathrm{S}) \\
0.87(\mathrm{Q} \text { vs } \mathrm{S}) \\
0.86(\mathrm{Q} \text { vs } \mathrm{A}) \\
0.82(\mathrm{~B} \text { vs } \mathrm{A}) \\
0.80(\mathrm{Q} \text { vs } \mathrm{D}) \\
0.92(\mathrm{~B} \text { vs } \mathrm{D})\end{array}$ & $\begin{array}{l}0.61(\mathrm{H} \text { vs } \mathrm{B}) \\
0.75(\mathrm{Q} \text { vs } \mathrm{B}) \\
0.78(\mathrm{~B} \text { vs } \mathrm{S}) \\
0.79(\mathrm{H} \text { vs } \mathrm{A}) \\
0.68(\mathrm{H} \text { vs } \mathrm{A})\end{array}$ & 0.48 (B vs $\mathrm{P}$ ) & $\begin{array}{l}0.15(\mathrm{~S} \text { vs } \mathrm{C}) \\
0.14(\mathrm{C} \text { vs } \mathrm{A}) \\
0.08(\mathrm{C} \text { vs } \mathrm{D})\end{array}$ \\
\hline ※ & $\begin{array}{l}\text { 1. The symbol of res } \\
\text { 2. G represents high } \\
\text { 3. M represents med } \\
\text { 4. L represents low } \\
\text { 5. EL represents ext }\end{array}$ & $\begin{array}{l}\text { ve parameter; } \\
\text { lation }(|\mathrm{r}| \geqq \\
\text { correlation }(0.5 \\
\text { ation }(0.3 \leqq \mid \\
\text { y low correlati }\end{array}$ & $\begin{array}{l}\operatorname{Tmax}(\mathrm{T}), \mathrm{HI}(\mathrm{H} \\
0.8) \text {. } \\
<0.3) \text {. }\end{array}$ & , BI(B), PI(P), S & $\mathrm{C}(\mathrm{C}),[\mathrm{S} 1+\mathrm{S} 2](\mathrm{A}), \mathrm{S} 1(\mathrm{D})$ \\
\hline
\end{tabular}

Table 13. Mean and 95\% confidence interval of datasets of 226 samples, CJ1-38, TW1-48, ML1-59, and AU1-13 samples

\begin{tabular}{|c|c|c|c|c|c|}
\hline \multirow{3}{*}{ Parameters } & \multicolumn{5}{|l|}{ Data sets } \\
\hline & 226 samples & 38 samples & 48 samples & 59 samples & 13 samples \\
\hline & \multicolumn{5}{|c|}{ (Mean) 95\% Confidence Interval for Mean } \\
\hline \multirow{3}{*}{$\%$ Ro } & $(0.73)$ & $(0.68)$ & $(0.58)$ & $(0.71)$ & $(1.15)$ \\
\hline & $0.72 \sim 0.75$ & $0.65 \sim 0.72$ & $0.44 \sim 0.63$ & $0.27 \sim 1.10$ & $0.93 \sim 1.28$ \\
\hline & (439.3) & $(442.1)$ & $(428.2)$ & (441.6) & (427.6) \\
\hline \multirow{2}{*}{$\mathrm{T} \max \left({ }^{\circ} \mathrm{C}\right)$} & $437.2 \sim 439.2$ & $439.3 \sim 442.7$ & $422.2 \sim 433.2$ & $426.1 \sim 460.3$ & $423.8 \sim 434.1$ \\
\hline & $(237.2)$ & (326.6) & (208.6) & $(254.3)$ & $(137.2)$ \\
\hline HI & $229.3 \sim 259.6$ & $265.6 \sim 384.4$ & $174.1 \sim 233.3$ & $157.9 \sim 354.4$ & $88.1 \sim 185.9$ \\
\hline \multirow{2}{*}{ QI } & $(243.3)$ & $(352.3)$ & $(219.2)$ & $(266.5)$ & $(158.9)$ \\
\hline & $229.3 \sim 259.6$ & $286.7 \sim 411.5$ & 177.5 237.4) & $161.5 \sim 368.9)$ & $103.9 \sim 222.6$ \\
\hline BI & $\begin{array}{l}(11.8) \\
9.74 \sim 13.41\end{array}$ & $\begin{array}{l}(24.1) \\
17.6 \sim 30.3\end{array}$ & $\begin{array}{l}(4.28) \\
3.25 \sim 5.37\end{array}$ & $\begin{array}{l}(9.46) \\
2.88 \sim 15.68\end{array}$ & $\begin{array}{l}(27.1) \\
11.1 \sim 41.5\end{array}$ \\
\hline \multirow{2}{*}{ PI } & $(0.043)$ & $(0.073)$ & $(0.023)$ & $(0.074)$ & $(0.172)$ \\
\hline & $0.038 \sim 0.050$ & $0.058 \sim 0.086$ & $0.018 \sim 0.027$ & $-0.028 \sim 0.179$ & $0.096 \sim 0.239$ \\
\hline \multirow{2}{*}{ S2 } & (111.2) & $(40.6)$ & (116.9) & $(106.2)$ & $(3.12)$ \\
\hline & $97.9 \sim 121.9$ & $20.9 \sim 55.3$ & $88.9 \sim 133.2$ & $58.1 \sim 150.8$ & $1.38 \sim 5.42$ \\
\hline \multirow{2}{*}{ TOC } & $(47.2)$ & (13.4) & $(54.2)$ & $(52.7)$ & $(3.27)$ \\
\hline & $42.2 \sim 51.5$ & $5.6 \sim 18.7$ & $46.9 \sim 59.6$ & $39.3 \sim 67.1$ & $0.34 \sim 5.99$ \\
\hline \multirow{2}{*}{$\mathrm{S} 1+\mathrm{S} 2$} & (113.6) & $(42.3)$ & $(117.8)$ & $(110.2)$ & $(3.98)$ \\
\hline & $101.5 \sim 126.2$ & $22.2 \sim 58.8$ & $90.8 \sim 135.6$ & $60.1 \sim 154.1$ & $1.39 \sim 6.75$ \\
\hline \multirow{2}{*}{ S1 } & $(3.74)$ & $(2.42)$ & $(2.21)$ & $(3.21)$ & $(0.65)$ \\
\hline & $3.29 \sim 4.49$ & $1.11 \sim 3.60$ & $1.63 \sim 2.67$ & $1.04 \sim 4.21$ & $-0.01 \sim 1.35$ \\
\hline
\end{tabular}

(a) The 226 samples were obtained from the second part (the region of highest petroleum potential with Ro $=0.6-1.0 \%, \mathrm{HI}>100$, cf. Figure 10 ) in the cross-plot of HI vs. \%Ro for dataset of 608 samples.

(b) The 38 samples obtained from CJ1-38 (Chen, 2003, cf. table 6; TW1-48, ML1-21, AU1-13 cf. table 11).

\section{Conclusion}

The results from statistical analysis of 10 parameters data for all samples in this research work, not only be executed a linear regression, curve regression between any two parameters, and multivariate regression, but also be carried on the forecast of grey correlation grade of grey theory (include grey relational generating (Nominal-the-better-: Ro\%; Larger-the-better-: $\mathrm{T}_{\max }, \mathrm{HI}, \mathrm{QI}, \mathrm{BI}, \mathrm{S} 2, \mathrm{~S} 1+\mathrm{S} 2, \mathrm{~S} 1$; smaller-the-better-: TOC, PI) and globalization grey relational 
grade). The highest petroleum potential is located in the range with $\% \mathrm{Ro}=0.6-1.0 \%$, and $\mathrm{HI}>100$. The oil expulsion window is located in the range with $\% \mathrm{Ro}=0.75-1.05 \%$ or $\mathrm{T}_{\max }=440-455^{\circ} \mathrm{C}$. The range of by $\mathrm{Ro} \%, \mathrm{~T}_{\max }$, cross-plots, Grey Model and statistical analysis are all in good agreement.

The hierarchial cluster analysis dendrogram ( $Q$ mode) based on data from 10 parameters of TW1-48 and CJ1-38 samples reveals a high similarity between the majority of CJ1-38 samples. In addition, the majority of CJ1-38 samples possess high petroleum potential in the second part (II), and the maturation of TW1-48 samples from immaturity to the oil window falls into first and second parts ( I and II ). Experimental and statistical analytical investigation reveals that the values of eight parameters (HI, QI, BI, PI, S2, S1+ $\mathrm{S} 2$, and S1) increase as the thermal maturity of organic materials increases during the initial stage of thermal maturation. At maturities greater than $\mathrm{Ro}=0.6-1.0 \%(\mathrm{Tmax}=$ $430-450^{\circ} \mathrm{C}$ ), the values of these parameters start to decrease gradually. At Ro $>1.0 \%$, the values of those parameters decrease rapidly, with a corresponding drop in petroleum potential.

Based on statistical analysis and cross-plots of HI, QI and $\mathrm{BI}$ versus the vitrinite reflectance $(\% \mathrm{Ro})$ and $\mathrm{Tmax}\left({ }^{\circ} \mathrm{C}\right)$, the $\mathrm{HI}_{\max }, \mathrm{QI}_{\max }$ and $\mathrm{BI}_{\max }$ lines are defined between the vertex of the upper and lower limits of the HI-band, QI-band and BI-band as defined by a majority of the samples. The constructed HI, QI and BI bands were broad at low maturities and gradually narrowed with increasing thermal maturity. The petroleum generation potential is completely exhausted at a vitrinite reflectance of $2.0-2.2 \%$ or a $\mathrm{T}_{\max }$ of $510-520^{\circ} \mathrm{C}$. An increase in HI and QI suggests extra petroleum potential related to changes in the structure of the organic material. A decline in BI signifies the start of the oil expulsion window and occurs within the vitrinite reflectance range $0.75-1.05 \%$ or a $\mathrm{T}_{\max }$ of $440-455{ }^{\circ} \mathrm{C}$. Furthermore, petroleum potential can be divided into four different parts based on the cross-plot of HI vs. \%Ro. The area with the highest petroleum potential is located in section II with $\% \mathrm{Ro}=0.6-1.0 \%$, and $\mathrm{HI}>100$. Oil generation potential is rapidly exhausted at section III with $\%$ Ro $>1.0 \%$. This result is in accordance with the regression curve of $\mathrm{HI}$ and QI with $\%$ Ro based on 97 samples with $\%$ Ro $=1.0 \sim 5.6 \%$. The exponential equation of regression can thus be achieved: curve, $H I=994.8 e^{-1.7 R o}$ and $Q I=1646.2 e^{-2.0 R o} \quad\left(\mathrm{R}^{2}=0.72\right)$.

The worldwide organic material dataset defines two oil expulsion windows represented by the upper and lower limits of the BI band: $\%$ Ro $\sim 0.75$ to $\sim 1.95 \%$ or $\mathrm{T}_{\max } \sim 440$ to $\sim 525^{\circ} \mathrm{C}$, and $\%$ Ro $\sim 1.05$ to $\sim 1.25 \%$ or $\mathrm{T}_{\max } \sim 455$ to $\sim 465^{\circ} \mathrm{C}$, respectively. The start of the oil expulsion window occurs within the $\%$ Ro range of $\sim 0.75-1.05 \%$ Ro or the $\mathrm{T}_{\max }$ range $\sim$ $440-455^{\circ} \mathrm{C}$ and the total oil window extends to $\%$ Ro $=\sim$ $1.25-1.95$ or $\mathrm{T}_{\max }=\sim 465-525^{\circ} \mathrm{C}$.

As the results of this study, we expect to promote evaluation techniques for $\mathrm{HC}$ exploration and propose new guidelines for evaluating the petroleum potential of organic matter. A significant petroleum generation build-up occurs at an approximate Ro\% interval of 0.6 to 0.75 , as indicated by a worldwide sample dataset of Coal and Carbonaceous Materials. $\mathrm{S}_{2}$ yields and $\mathrm{HI}$ values stabilize at low values - approximately at a vitrinite reflectance of $2.2 \%$, which indicates the exhaustion of the petroleum generative potential. For general purposes, the "oil window" for organic materials in this study is defined within a Ro ranging from $0.75-1.95 \%$. This re-considered "oil window" is very probably also valid for source rocks of Coal and Carbonaceous Materials. Moreover, samples with $\mathrm{Ro} \%<0.6$ or $\mathrm{Ro} \%=0.6-1.0$ and $\mathrm{HI}<100$ are the least effective oil source rocks, and samples with $\mathrm{Ro} \%=0.6-1.0$ and $\mathrm{HI}>100$ are the most effective oil source rocks.

\section{Acknowledgements}

Author would like to give thanks to anonymous reviewers of this manuscript for giving constructive suggestions and revision comments. Special thanks to all of the faculties and staff of the Geochemical Department of Exploration and Development Research Institute, CPC., for providing valuable samples and analyzing assistance. This research was financially supported by Grants NSC-102-2116-M-252-001of National Science Council.

\section{References}

[1] Akande SO, Ojo OJ, Erdtmann BD, Hetenyi M (1998) Paleoenvironments, source rock potential and thermal maturity of the Upper Benue rift basins, Nigeria : implications for hydrocarbon exploration. Organic Geochemistry29 (1-3): $531-542$

[2] Amijaya H, Littke R (2006) Properties of thermally metamorphosed coal from Tanjung Enim Area, South Sumatra Basin, Indonesia with special reference to the coalification path of macerals. International Journal of Coal Geology 66:271-295

[3] Arfaoui A, Montacer M, Kamoun F, Rigane A (2007) Comparative study between Rock-Eval pyrolysis and biomarkers parameters: A case study of Ypresian source rocks in central-northern Tunisia. Marine and Petroleum Geology $24: 566-578$

[4] ASTM (1975) Standard D-2797, ASTM Standard manual. Part 26:350-354

[5] ASTM (1980) Standard D-2797, Microscopical determination of volume percent of physical components in a polished specimen of coal, ASTM. Philadelphia, Pa.

[6] Banerjee A, Sinha AK, Jain AK, Thomas NJ, Misra KN, Chandra, K (1998) A mathematical representation of Rock-Eval hydrogen index vs. Tmax profiles. Organic Geochemistry28 (no.1/2):43-55

[7] Bordenave ML, Espitalie' J, Leplat P, Oudin JL, Vandenbroucke M (1993) Screening techniques for source rock evaluation, In: Bordenave, M.L. (Ed.), Applied Petroleum Geochemistry. Editions Technip, Paris, pp 219-224

[8] BostickNH, Daws TA (1994) Relationships between data from Rock-Eval pyrolysis and proximate, ultimate, petrographic, and physical analyses of 142 diverse U. S. coal samples. Organic Geochemistry21:35-49 
[9] Canonico U, Tocco R, Ruggiero A, Suarez H (2004) Organic geochemistry and petrology of coals and carbonaceous shales from western Venezuela. International Journal of Coal Geology 57:151-165

[10] Chen J, Liang D, Wang X, Zhong N, Song F, Deng C, Shi X, Jin T, Xiang S (2003)Mixed oils derived from multiple source rocks in the Cainan oilfield, Junggar Basin, Northwest China. Part I : genetic potential of source rocks, features of biomarkers and oil sources of typical crude oil. Organic Geochemistry 34:889-909

[11] Chen J-P, Deng C-P, Wang H-T, Han D-X (2006) Genetic potential and geochemical features of pyrolysis oils of macerals from Jurassic coal measures, Northwest China. Geochimica 1:81-87

[12] Chiu J-H, Kuo C-L, Lin H-J, Chou T-H (1993) Geochemical modeling of source rock hydrocarbon generation potential. Exploration Development Research Report 16: 232-256

[13] Chiu J-H, Kuo C-L, Wu S-H, Lin L-H, Shen J-C, Chou T-H (1996) Simulation of the hydrocarbon generation potential of the coal samples. Exploration Development Research Report $19: 420-453$

[14] Cooles GP, Mackenzie AS, Quigley JM (1986) Calculation of petroleum masses generated and expelled from source rocks. Organic Geochemistry 10:235-245

[15] Dahl B, Bojesen-Koefoed J, Holm A, Justwan H, Rasmussen E, Thomsen E (2004) A new approach to interpreting Rock-Eval S2 and TOC data for kerogen quality assessment. Organic Geochemistry35:1461-1477

[16] Davis RC, Noon SW, Harrington J (2007) The petroleum potential of Tertiary coals from Western Indonesia: Relationship to mire type and sequence stratigraphic setting. International Journal of Coal Geology 70:35-52

[17] Deng J-L (1988) Essential topics on grey system: theory and application, China Ocean Press, pp 327

[18] Espitalie'J, Deroo G, Marquis F (1985) La pyrolyse Rock-Eval et ses applications. Revue Institut Franc- ais du Pe' trole Part I40:563-578, Part II40:755-784

[19] Espitalie' J, Laporte JL, Madec M, Marquis F, Leplat P, Paulet J, Boutefeu F (1977) Me' thode rapide de caracte' risation des roches me' res, de leur potentiel pe' trolier et de leur degre' d'e' volution. Revue Institut Franc- ais du Pe' trole 32:23-42

[20] Hu C-J (2001) The application of Rock-Eval 6 in geochemical exploration. Exploration Development Research Report $23: 367-378$

[21] Hunt JM (1996) Petroleum Geochemistry and Geology. W.H. Freeman and Company, New York, pp 743

[22] ISO 7404-5 (1994E)Methods for the petrographic analysis of bituminous coal and anthracite Part 5 Method of determining microscopically the reflectance of vitrinite, International Standard, $2^{\text {nd }}$ ed., pp 1-13

[23] Karakitsios V, Rigakis N (2007) Evolution and petroleum potential of Western Greece, Journal of Petroleum Geology 30(3):197-218

[24] Katz BJ (1983) Limitation of 'Rock-Eval' pyrolysis for typing organic matter, Organic Geochemistry 4:195-199
[25] Keller G (2001) Applied statistics with Microsoft Excel, Thomson Learning Asia Pte Ltd, Beijing, pp 670

[26] Killops SD, Funnell RH, Suggate RP, Sykes R, Peters KE, Walters C, Woolhouse AD, Weston RJ(1998) Predicting generation and expulsion of paraffinic oil from vitrinite-rich coals. Org. Geochem 29(1-3):1-21

[27] Killops SD, Funnell RH, Suggate RP, Sykes R, Peters KE, Walters C, Woolhouse AD, Weston RJ, Boudou J-P (1998) Predicting generation and expulsion of paraffinic oil from vitrinite-rich coals. Organic Geochemistry 29:1-21

[28] Kotarba MJ, ClaytonJL, Rice DD, Wagner M (2002) Assessment of hydrocarbon source rock potential of Polish bituminous coals and carbonaceous shales, Chemical Geology184:11-35

[29] Kotarba MJ, Wiectaw D, Koltun YV, Marynowski L, Kusmierek J, Dudok IV (2007) Organic geochemistry study and genetic correlation of natural gas, oil and Menilite source rocks in the area between San and Stryi rivers (Polish and Ukrainian Carpathians). Organic Geochemistry 38(8): $1431-1456$

[30] Kotarba M, Lewan MD (2004) Characterizing thermogenic coalbed gas from Polish coals of different ranks by hydrous pyrolysis. Organic Geochemistry35:615-646

[31] Lee H-T (2011) Analysis and characterization of samples from sedimentary strata with correlations to indicate the potential for hydrocarbons, Environmental Earth Sciences 64:1713-1728

[32] Lee, H-T, Sun, L-C (2013) The atomic H/C ratio of kerogen and its relation to organic geochemical parameters : implications for evaluating hydrocarbon generation of source rock, Carbonates and Evaporites 28(4):433-445

[33] Liu D-H, Zhang H-Z, Dai J-X, Sheng G-Y, Xiao X-M, Sun Y-H, Shen J-G (2000) The research and evaluation of forming hydrocarbon from micro-constituent of coal rock. Chinese Science Bull.45(4):346-352

[34] Magoon LB, Dow WG (1994) The petroleum system-from source to trap. AAPG Memoir 60, Tulsa, Oklahoma, U.S.A., pp 655

[35] Newman J, Boreham CJ, Ward SD, Murray AP, Bal AA (1999) Floral influences on the petroleum source potential of New Zealand coals. In: Masterlerz, M., Glikson, M., Golding, S.D. (Eds.), Coalbed Methane: Scientific, Environmental and Economic Evaluation. Kluwer Academic pp 461-492

[36] Norgate CM, Boreham CJ, WilkinsAJ (1999) Changes in hydrocarbon maturity indices with coal rank and type, Buller Coalfield, New Zealand. Organic Geochemistry30:985-1010

[37] Pedersen GK, Andersen LA, Lundsteen EB, Petersen HI, Bojesen-Koefoed JA, Nytoft HP (2006) Depositional environments, organic maturity and petroleum potential of the Cretaceous Coal-Bearing Atane Formation at Qullissat, Nuussuaq Basin, West Greenland. Journal of Petroleum Geology 29(1):3-26

[38] Pepper AS, Corvi PJ (1995) Simple kinetic models of petroleum formation. Part I: oil and gas generation from kerogen. Marine Petroleum Geology 12 (3):291-319

[39] Peters KE, Cassa MR (1994) Applied source-rock geochemistry, In: Magoon, L.B., Dow, W.G. (Eds.), The Petroleum System-From Source to Trap. American Association of Petroleum Geologists, Memoir 60:93-120 
[40] Peters KE (1986) Guidelines for evaluating petroleum source rocks using programmed pyrolysis. American Association of Petroleum Geologists Bulletin 70:318-329

[41] Petersen HI (2002) A reconsideration of the "oil window" for humic coal and kerogen type III source rocks. Journal of Petroleum Geology 25(4):407-432

[42] Petersen HI (2006) The petroleum generation potential and effective oil window of humic coals related to coal composition and age. International Journal of Coal Geology 67:221-248

[43] Petersen HI, Nytoft HP, Nielsen LH (2004) Characterisation of oil and potential source rocks in the northeastern Song Hong Basin, Vietnam: indications of a lacustrine-coal sourced petroleum system. Organic Geochemistry 35:493-515

[44] Petersen HI, Rosenberg P, Andsbjerg J (1996) Organic geochemistry in relation to the depositional environments of Middle Jurassic coal seams, Danish Central Graben, and implications for hydrocarbon generative potential. AAPG Bulletin 80(1):47-62

[45] Petersen HI, Tru V, Nielsen LH, Due NA, Nytoft HP (2005) Source rock properties of lacustrine mudstones and coals (Oligocene Dong Ho formation), onshore Song Hong Basin, Northern Vietnam. Journal of Petroleum Geology28(1):19-38

[46] Powell TG, Boreham CJ, Smyth M, Russell N, Cook AC (1991) Petroleum source rock assessment in non-marine sequences : pyrolysis and petrographic analysis of Australian coals and carbonaceous shales. Organic Geochemistry17(3):375-394

[47] RabbaniAR, Kamali MR (2005) Source rock evaluation and petroleum geochemistry offshore SW Iran. Journal of Petroleum Geology 28(4):413-428

[48] Sachsenhofer RF, Privalov VA, Izart A, Elie M, Kortensky J, Panova E A, Sotirov A, Zhykalyak MV (2003) Petrography and geochemistry of Carboniferous coal seamsin the Donets Basin (Ukraine): implications for paleoecology. International Journal of Coal Geology55:225-259

[49] Suggate RP, Boudou JP (1993) Coal rank and type variation in Rock-Eval assessment of New Zealand coals, J. Pet. Geol. $16: 73-88$

[50] Sun X-G, Qin S-F, Luo J, Jin K-L (2001) A study of activation energy of coal macerals. Geochimica 30(6):559-604

[51] Sykes R (2001) Depositional and rank controls on the petroleum potential of coaly source rocks. In: Hill, K.C., Bernecker, T. (Eds.), Eastern Australasian Basins Symposium, a Refocused Energy Perspective for the Future. Petrol. Expl. Soc. Austral., Spec. Publ.pp 591-601

[52] Sykes R, Snowdon LR (2002) Guidelines for assessing the petroleum potential of coaly source rocks using Rock-Eval pyrolysis. Org. Geochem. 33:1441-1455

[53] Taylor GH, Teichmüller M, Davis A, Diessel CFK, Littke R, Robert P (1998) Organic Petrology. Gebrüder Borntraeger, Berlin, Stuttgart, pp 704

[54] Teichmüller M, Durand B (1983) Fluorescence microscopical rank studies on liptinites and vitrinites in peat and coals, and comparison with results of the Rock-Eval pyrolysis. Int. J. Coal Geol. 2:197-230

[55] Tissot BP, Welte DH (1984) Petroleum formation and occurrence ; a New approach to oil gas exploration. Springer-Verlag, Berlin, Heidelberg, New York, pp 699

[56] Tissot BP, Pelet R, Ungerer P (1987) Thermal history of sedimentary basins, maturation indices, and kinetics of oil and gas generation. AAPG Bull. 71:1445-1466

[57] Vassoevich NB, Akramkhodzhaev AM, Geodekyan AA (1974) Principal zone of oil formation. In: Tissot, B., Bienner, F. (Eds.), Advances in Organic Geochemistry 1973, Éditions Technip, Paris,pp309-314

[58] Veld H, Fermont WJJ, Jegers LF (1993) Organic petrological characterization of Westphalian coals from The Netherlands : correlation between Tmax, vitrinite reflectance and hydrogen index. Organic Geochemistry20(6):659-675

[59] Wang C-J (1998) A "folded-fan" method for assessment on the hydrocarbon generating potential of coals. Geochimica 27(5):4 83-492

[60] Wen K-L (2004) Grey Systems Modeling and Prediction, Yang's Scientific Research Institute, USA, pp 468

[61] Wu S-H, Weng R-N, Shen J-Q, Sun Z-X, Guo Z-L (2003) The study for constituent characteristics of the hydrocarbon compound of coal and coal shales in the NW Taiwan, Exploration Development Research Report 25:229-239

[62] Xiao XM, Hu ZL, Jin YB, Song ZG (2005) Hydrocarbon source rocks and generation history in The Lunnan Oilfield area, northern Tarim Basin (NW China). Journal of Petroleum Geology28(3):319-333

[63] Xiao X (1997) The organic petrological characteristics of Triassic source rocks and their hydrocarbon-generating potential in Tarim Basin. Geochimica 26(1):64-71

[64] Xiao X, Liu D, Fu J (1996) The evaluation of coal-measure source rocks of coal-bearing basins in China and their hydrocarbon-generating models. Acta Sedimentologica Sincia 14(supp.):10-17

[65] Zhang T-P, Zhang Y-C, Cai K-Z (2007) SPSS Statistic modeling and analytic procedure. Kings Information Co., Ltd., Taipei, pp 674 